\title{
Neutron Logging Measurements in the Single Heater Test First Quarter, FY98
}

\author{
W. Lin \\ R. Carlson \\ D. Watwood
}

January 16, 1998

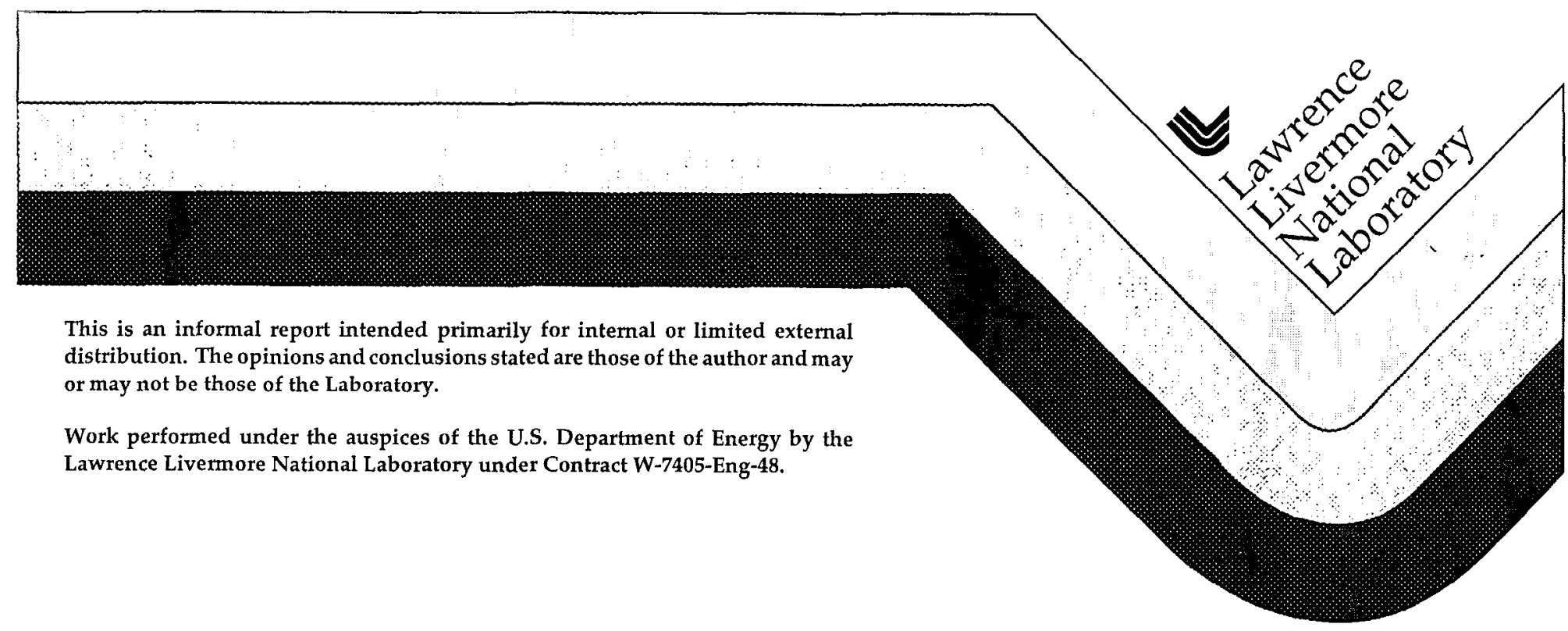




\section{DISCLAIMER}

This document was prepared as an account of work sponsored by an agency of the United States Government. Neither the United States Government nor the University of California nor any of their employees, makes any warranty, express or implied, or assumes any legal liability or responsibility for the accuracy, completeness, or usefulness of any information, apparatus, product, or process disclosed, or represents that its use would not infringe privately owned rights. Reference herein to any specific commercial product, process, or service by trade name, trademark, manufacturer, or otherwise, does not necessarily constitute or imply its endorsement, recommendation, or favoring by the United States Government or the University of California. The views and opinions of authors expressed herein do not necessarily state or reflect those of the United States Government or the University of California, and shall not be used for advertising or product endorsement purposes.

This report has been reproduced directly from the best available copy.

Available to DOE and DOE contractors from the Office of Scientific and Technical Information

P.O. Box 62, Oak Ridge, TN 37831

Prices available from (615) 576-8401, FTS 626-8401

Available to the public from the

National Technical Information Service

U.S. Department of Commerce

5285 Port Royal Rd.,

Springfield, VA 22161 


\section{Neutron Logging Measurements in the Single Heater Test}

First Quarter, FY98

Milestone SP1270M4

Wunan Lin, Richard Carlson, and Don Watwood

\section{Introduction}

The purpose of the Single Heater Test (SHT), the design of the test, and the borehole layout were reported by OCRWM M\&O (1996a). Briefly, the main purpose of the SHT is to study the thermalmechanical behavior of the densely welded non-lithophysal Topopah Spring tuff at the Exploratory Studies Facility (ESF). The SHT is also used as a shake-down for the test of the coupled thermalmechanical-hydrological-chemical (TMHC) processes. Figure 1 shows the test configuration and borehole layout of the SHT.

Thermal neutron logging is a method used to determine moisture content in rocks and soils and was used to monitor moisture content in boreholes 15, 17, 22, and 23, as shown in Figure 1 , during the SHT. The neutron probe contains a source of high energy neutrons and a detector for slow (thermal) neutrons. Water present in rocks slows down the neutrons making them detectable (because of the presence of hydrogen). Thus, higher counts (or a positive difference in counts relative to background or pre-heat levels) indicate higher water content (or increased water content over background). The probe used in this test is a Campbell Pacific Nuclear (CPN) model 503DR. The $3.81-\mathrm{cm}$ (1.5 inch) diameter probe was utilized for the SHT (Serial Number: H37067677). Under ambient conditions the sampling volume has a diameter approximately $15 \mathrm{~cm}$ surrounding the probe, increasing as moisture content decreases. Measurements are sensitive to the presence of elements that have large neutron capture cross-sections, such as chlorine and boron. The uncertainty of the neutron logging is about 3 to $5 \%$ in water content.

For the SHT a Teflon tube, with a resistance temperature device (RTD) bundle mounted on its outside, was inserted into the boreholes and grouted into place. The Teflon tube permits easy insertion, placement, and removal of the tool. Calibrations of the neutron tool in the Teflon liner-RTD-grout assembly identical to that used in the holes have been conducted by Richard Carlson and Dan Neubauer, as described later in this report. Relative change in 
water content is calculated from the neutron counts and the calibration results.

\section{Measurement Procedures}

The following procedure describes the method of collecting neutron data during the SHT. We used the $3.81-\mathrm{cm}$ diameter probe and a counting time of 16 seconds. Standard counts, which are the neutron counts when the tool is in the tool holder away from any influence of the rock mass to be measured, were measured and recorded immediately prior to, and subsequent to performing measurements. The neutron probe was placed in a borehole at a specific location and the neutron count recorded in a scientific notebook as well as electronically in the device memory. Upon completion of the test, data was downloaded to a computer and the data values checked against the hand recorded values. Data were recorded at depth intervals of $10 \mathrm{~cm}$ in each borehole.

During this quarter the neutron logging was conducted on September 25, October 29, November 24, and December 17,1997. The data in this quarter were smoothed both in the space and time domains using a three-point smoothing algorithm, which weighs the middle point by 0.6 and the two side points by 0.2 each, the same as in the previous quarter. The smoothing made the data look smoother, but did not change the amplitude of the differences in the fraction volume water significantly. All of the in-heat and cool-down data up to December 17, 1997 will be presented in this report. The test of the coupled TMHC processes focuses on the change in effect of heat on the behavior of the rock mass. Therefore the difference of the water content in the rock mass between the pre-heat background (measured on August 21, 1996) and the dates of measurement listed above will be presented. The heaters were turned on at 1:30 PM 26 August 96. The heater was turned off on May 28, 1997, which was 275 days since the heater was energized. Two neutron logs were conducted during the first month of the in-heat and cool-down phases. (For reference, the dates of electrical resistance tomography (ERT) measurements during this quarter September 25, October 21, and December 17 of 1997 . The ERT will be reported as a separt part of this milestone.).

\section{Calibration of the Neutron Tool}

The neutron measurement holes at the SHT are lined with Teflon tubing and the annulus is sealed with grout. The liner ID is $4.04 \mathrm{~cm}$ to just pass the $3.81 \mathrm{~cm}$ tool, and the liner has a $0.381 \mathrm{~cm}$ 
wall thickness. The holes were drilled at $7.62 \mathrm{~cm}$ to provide space for RTD wires to measure temperature in the same hole. The 1.41 $\mathrm{cm}$ annulus of water-rich grout was expected to change the response of the probe to formation water, so a special calibration for this geometry was required.

To calibrate the CPN moisture probe in terms of volume fraction water we installed $7.62-\mathrm{cm}$ thin wall $\mathrm{Al}$ tubing along the centerline of each of five 55-gallon drums, and filled each annular space with a mix of sand-like materials to achieve a known density and hydrogen content (water content equivalent). We then cast grout around a piece of the Teflon liner inside a slightly undersize piece of the Al tubing, so the grout/liner assembly would slide snugly inside the tubes in the drums. Counts were then taken with both the probe and the grout/liner assembly at various heights in each drum to check for homogeneity and edge effects in the vertical direction, with long counts taken in the central regions to improve statistics on the values actually used for calibration. Because RTDs were installed in the annular space between the Teflon liner and the borehole wall, the calibration procedures were also repeated in a grout/liner/RTD assembly. To check for neutron loss from the finite sized drums, we took additional counts with a $100 \mathrm{lb}$ bag of one of the mix constituents, tabular alumina, placed against the side of the drum, that increased the radius by $15 \mathrm{~cm}$. The raw counts were then adjusted for the loss as described below.

It is clear that the density of the rock will change over the course of the SHT; however we do not expect the solid parts of the rock to change appreciably, only the amount of water in the pores will change. Thus if we construct the calibration in terms of water and dry density, the density effects can be absorbed into constants. Initial information indicated the porosity at the SHT was approximately $10 \%$ and the density was about $2.2 \mathrm{gm} / \mathrm{cc}$. We chose to build three drums with dry density $2.2 \mathrm{gm} / \mathrm{cc}$, and 0,5 and 10 volume percent water (Drums $a, b$, and $c$ in the Table below), with an additional two drums with dry density $1.8 \mathrm{gm} / \mathrm{cc}$, and 0 , and 10 volume percent water (Drums $d$ and $e$ in the Table below) to control for density variations. The weight fraction water was precisely controlled by digital scales. Density, however, was determined after the mix was vibrated in place, by how high a given weight of mix increased the fill height in the drum. The recipe for the mix was determined by trial and error on small samples, and the entire drum filled in approximately $12.7 \mathrm{~cm}$ lifts of that recipe. For each lift the mix was vibrated, leveled, packed, and the fill height measured to within $0.16 \mathrm{~cm}$. The total fill height is about $81.28 \mathrm{~cm}$, 
so density and volume fraction water are known to about $2 \%$ of value in each lift, and to about $1 \%$ of value overall.

The five drums are represented as $a, b, c, d$, and $e$ in the table below. The first four rows of the table show the raw counts ("rawcount"), the density ("density") in gm/cc, the vol\% water ("H2O") and the dry density ("dry dens") in gm/cc obtained for the drums. The fifth row ("100lb TA") is the count obtained with the extra $100 \mathrm{lb}$ of material against the side of the drum, and the sixth row ("dcut/dTA") gives the change in count between row 1 and row 5 . The seventh row ("dw/d6"') is the weight of that drum's mix needed in order to add six inches $(15 \mathrm{~cm}$ ) to the drum radius (about the thickness of the $100 \mathrm{lb} \mathrm{bag}$ ), and the eighth row, labeled "loss", gives the expected count change if that were done, which equals dcut/dTA times dw/d6" divided by 100 . The "loss" is shown in term of the fraction of the total count in the ninth row ("fr loss"). The value in row 9 multiplied by the density in row 2 are shown in row ten ("fr loss*den"). The values in row 10 are nearly equal, except for drum $b$ which is very different. Eliminating the drum $b$ value and averaging the rest gives a value of 0.1424 , which is used to calculate the count on line eleven ("count"): Count (Line 11) = raw count (line 1$)^{\star}[1+0.1424 /$ density (line 2)]. The count in line 11 is the expected count for an infinite drum of that density and water content. But to make plots we need densities for which the dry density does not change with water content. Appropriate density values are shown on line twelve ("adj den"), which are calculated using a dry density of $2.1464 \mathrm{gm} / \mathrm{cc}$ and the associated water content. The counts in line 13 ("adj count") were then calculated by taking account the effect of density. The effect of density on the count was determined from the raw count (line 1) and density (line 2) data in columns a and $d$. The "adj count" (line 13) are used to calculate volume water content from measured counts.

There are a number of ways to fit equations to these calibration data. Water values given in this report are generated from count data using the equation for the line through the upper two water content points for dry density $2.1464 \mathrm{gm} / \mathrm{cc}$. These are the values closest to SHT conditions. We are planning further calibration work to better define the linearity of the probe response, especially in the region above $10 \%$ water where we currently must extrapolate.

Table 1. Probe Calibration Data. 


\begin{tabular}{|c|c|c|c|c|c|}
\hline Drum & a & $b$ & c & $d$ & e \\
\hline 1. rawcount & 3358 & 6453 & 9078 & 2512 & $7 \overline{774}$ \\
\hline $\begin{array}{l}\text { 2. density } \\
(\mathrm{gm} / \mathrm{cc})\end{array}$ & 2.155 & 2.195 & 2.201 & 1.789 & 1.839 \\
\hline 3. $\mathrm{H} 2 \mathrm{O}$ & 0 & 0.0486 & 0.096 & 0 & 0.0967 \\
\hline $\begin{array}{l}\text { 4. dry dens } \\
(\mathrm{gm} / \mathrm{cc})\end{array}$ & $2.15 \overline{5}$ & 2.1464 & 2.105 & 1.789 & 1.7423 \\
\hline $5.100 \mathrm{lb} \mathrm{TA}$ & 3414 & 6622 & $922 \overline{7}$ & $2 \overline{5} \overline{5}$ & 7955 \\
\hline 6. dent/dTA & 56 & 169 & $14 \overline{9}$ & 63 & 181 \\
\hline 7. $\mathrm{dw} / \mathrm{d} 6 "$ & $418 . \overline{7}$ & 426.4 & 427.6 & $34 \overline{7} .5$ & 357.3 \\
\hline 8. loss & 234.4 & 720.7 & $63 \overline{7} .1$ & 219.0 & 646.6 \\
\hline 9. fr loss & 0.06526 & 0.10046 & 0.06558 & 0.08018 & 0.07679 \\
\hline 10. fr loss ${ }^{\star}$ den & 0.14064 & 0.22051 & 0.14434 & 0.14343 & 0.14122 \\
\hline 11. count & 3580 & 6872 & 9665 & 2712 & 8376 \\
\hline $\begin{array}{c}\text { 12. adj den } \\
(\mathrm{gm} / \mathrm{cc})\end{array}$ & 2.146 & 2.195 & 2.242 & 1.789 & 1.886 \\
\hline 13. adj count & 3560 & $68 \overline{72}$ & $981 \overline{3}$ & 2712 & 8542 \\
\hline
\end{tabular}

\section{Data and Discussion}

All of the moisture content data determined by neutron logging up to this quarter will be included in this report. The fraction volume water calculated from the neutron counts at every $10 \mathrm{~cm}$ in each hole will be presented in this report. The fraction volume water content at some locations in each hole as a function of time will also be presented. The neutron results are presented as the difference in water content between the in-heat measurements, which were conducted after the heater was energized on August 26, 1996, and the pre-heat background data, which were obtained on August 21, 1996. Therefore in the following figures the positive fraction volume water means gaining moisture content, and negative fraction volume water means drying. The fraction volume water results in the following figures are presented on the same scale so that comparisons can be easily made. Saturation level in the rock 
mass can be calculated by dividing the fraction volume water by the fraction porosity of the rock mass. For example, if the porosity of the rock is 0.1 , a difference fraction volume water of 0.01 equals a change of $10 \%$ in saturation level.

Figures 2 to 10 show the difference fraction volume water in Hole\#15 as a function of depth from the collar on various dates of in-heat and cool-down phase measurements. Figure 11 shows the water content in this hole at various depths from collar as a function of time. The 0 day in Figure 11 was when the heater was turned on. Hole\#15 is above the heater with an inclination of about 17 degrees (OCRWM M\&O, 1996a). The shortest distance between the hole and the heater is about $2.07 \mathrm{~m}$, at about $5.75 \mathrm{~m}$ from the collar of the hole. The peak temperature in this hole before the heater was de-energized was about $62^{\circ} \mathrm{C}$. A slight decrease in fraction volume water content began to develop at the closest point between the heater and the hole in October of 1996. This decrease in the water content reached about 0.006 on $5 / 21 / 97$. If we assume a porosity of 0.14 (OCRWM M\&O, 1996b) the maximum saturation level decrease was about $4 \%$. A similar decrease in the moisture content was also observed at about $1.5 \mathrm{~m}$ from the collar of the hole. During the cooling phase the neutron results show a slight re-wetting, especially at the closest point between the heater and the hole, as shown by Figures 7 to 11 .

The neutron logging results in Hole\#17 as a function of depth from the collar on various dates of the in-heat and cool-down phase measurements are shown in Figures 12 to 20. Figure 21 shows the water content in this hole at various depths from collar as a function of time. The 0 day in Figure 21 was when the heater was turned on. Hole\#17 is below the heater with a decline angle of about 7 degrees (OCRWM M\&O, 1996a). The shortest distance between the heater and this hole is about $1.2 \mathrm{~m}$, at about $6.48 \mathrm{~m}$ from the collar of the hole. The peak temperature in this hole before the heater was turned off was about $90^{\circ} \mathrm{C}$. A well defined trend of drying was observed on 11/26/96 at just below the closest point to the heater. The maximum decrease in the fraction volume water content in this hole was about 0.014 , which equals a decrease in saturation level of about $10 \%$, again assuming a porosity of 0.14 . This region of decrease in the water content later extended to the bottom of the hole. The width of the drying region in this hole is greater than that in other holes. An increase in the water content was also observed near the collar of the hole. The amplitude of that increase in the water content was about 0.01 . Figures 17 to 21 show that no change in the moisture content was observed during the cool-down phase, 
except at $4.46 \mathrm{~m}$ from the collar where the decrease in the water content was slightly recovered since the cool-down phase started (Figure 21).

Figures 22 to 30 show the difference fraction volume water content in Hole\#22 as a function of depth from the collar on various dates of the in-heat and cool-down phase measurements. Figure 31 shows the water content in this hole at various depths from collar as a function of time. The 0 day in Figure 31 was when the heater was turned on. Hole\#22 is almost horizontal, about $0.65 \mathrm{~m}$ below the heater horizon. The end of this hole is about $1.6 \mathrm{~m}$ from the heater (OCRWM M\&O, 1996a). The peak temperature in this hole before the heater was turned off was about $74^{\circ} \mathrm{C}$. A slight drying region near the bottom of the hole was observed near the end of the heating phase (Figure 26). The decrease in the fraction volume water content in that region was about 0.008 , slightly greater than that in Hole\#15. Again, Figures 29 to 31 show some changes in the moisture content during the cool-down phase. The cause of the spike at about $1.2 \mathrm{~m}$ depth from the collar on 6/24/97 (Figure 27) is not clear. Because it is an isolated occurrence it probably has no significant implication on the moisture distribution in the rock mass. Figure 31 shows that during the last three measurements the outer half of the hole showed re-wetting, but the inner half showed further drying. The cause for these changes is still being investigated.

The difference fraction volume water content in Hole\#23 as a function of depth from the collar on various dates during the heating and cool-down phases are shown in Figures 32 to 40 . Figure 41 shows the water content in this hole at various depths from the collar as a function of time. The 0 day in Figure 41 was when the heater was turned on. Hole\#23 reaches the upper-left side of the heater with an incline angle of about 7.5 degrees. The end of this hole is about $1.23 \mathrm{~m}$ from the heater (OCRWM M\&O, 1996a). The peak temperature in this hole was about $88^{\circ} \mathrm{C}$. A drying region near the bottom of this hole began to develop about two months into the heating phase. The maximum decrease in the fraction volume water content in this hole was about 0.016 , which equals about $11 \%$ in saturation level for a porosity of 0.14 . The spike at $1.2 \mathrm{~m}$ from the collar on 5/21/97 (Figure 36) is an isolated occurrence, and probably has no significant implication on the moisture distribution in the rock mass. Figures 37 to 41 show no significant changes in the water content during the cool-down phase, except in the region deeper than $4.7 \mathrm{~m}$, where re-wetting has been observed (Figure 41). 


\section{Other Observations}

Vapor condensation was observed in Holes \#22 and \#23 during the later part of the heating phase (April and May of 1997). The inner surfaces of the liners in those holes were wiped dry before each logging. Some condensed water was collected from the liner of Hole\#23. Chemical analyses on the water samples are being conducted. During the first month of the cool-down phase vapor condensation was still observed in Holes \#22 and \#23, but no condensed water was in Hole\#23 to be collected. Later during the third month of the cooling phase no condensation was observed in Holes \#22 and \#23. During both the heating and cool-down phases no vapor condensation was observed in Holes \#15 and \#17.

\section{Summary}

Neutron logging in the Single Heater Test region observed changes in the moisture content in the heated rock mass. The degree of drying seemed in good correlation with the temperatures in the rock. The decreases of the water content in the drying regions were small, because the neutron logging holes are not close to the heater. It is indicated by the results that the drying region below the heater seems to be more wide-spread than in other regions. Re-wetting was observed at a few localized regions during the first three months of cooling. The amplitude of the re-wetting was small.

\section{Future Plans}

The SHT progresses into the post-test phase. The neutron logging is terminated. An additional calibration point at a greater moisture content level and with a density closer to that of the dry rock will be obtained. With the additional calibration point and a better control of the density the calculated water content of the rock mass will be more accurate. All of the data from measurements before 7/23/97 will be smoothed later. 


\section{References}

Civilian Radioactive Waste Management System Management and Operation Contractor (OCRWM M\&O), 1996a, Test Design, Plans, and Layout for the First ESF Thermal Test, Rev. 1, BAB000000-017174600-00025, TRW Environmental Safety System, Inc., Las Vegas, NV 89109 .

Civilian Radioactive Waste Management System Management and Operation Contractor (OCRWM M\&O), 1996b, Characterization of the ESF Thermal Test Area, B00000000-01717-5705-00047 Rev 01, TRW Environmental Safety System, Inc., Las Vegas, NV 89109. 


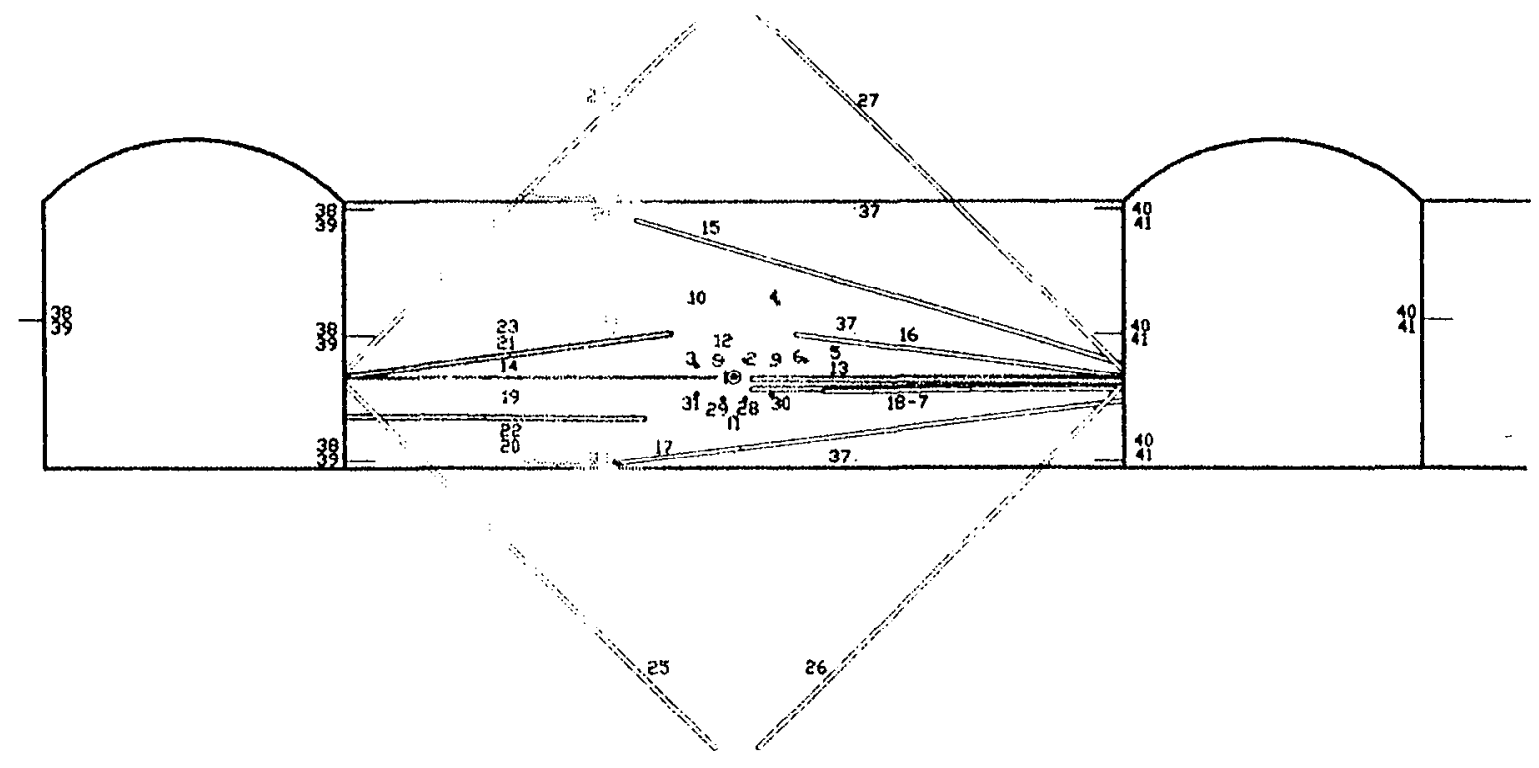

Figure 1(a). Vertical cross section of the borehole layout of the Single Heater Test. Siee CRWMS M\&O (1996a) for description of the boreholes. The riseholes are identified by the numbers. The colors do not haide significant meaning. 


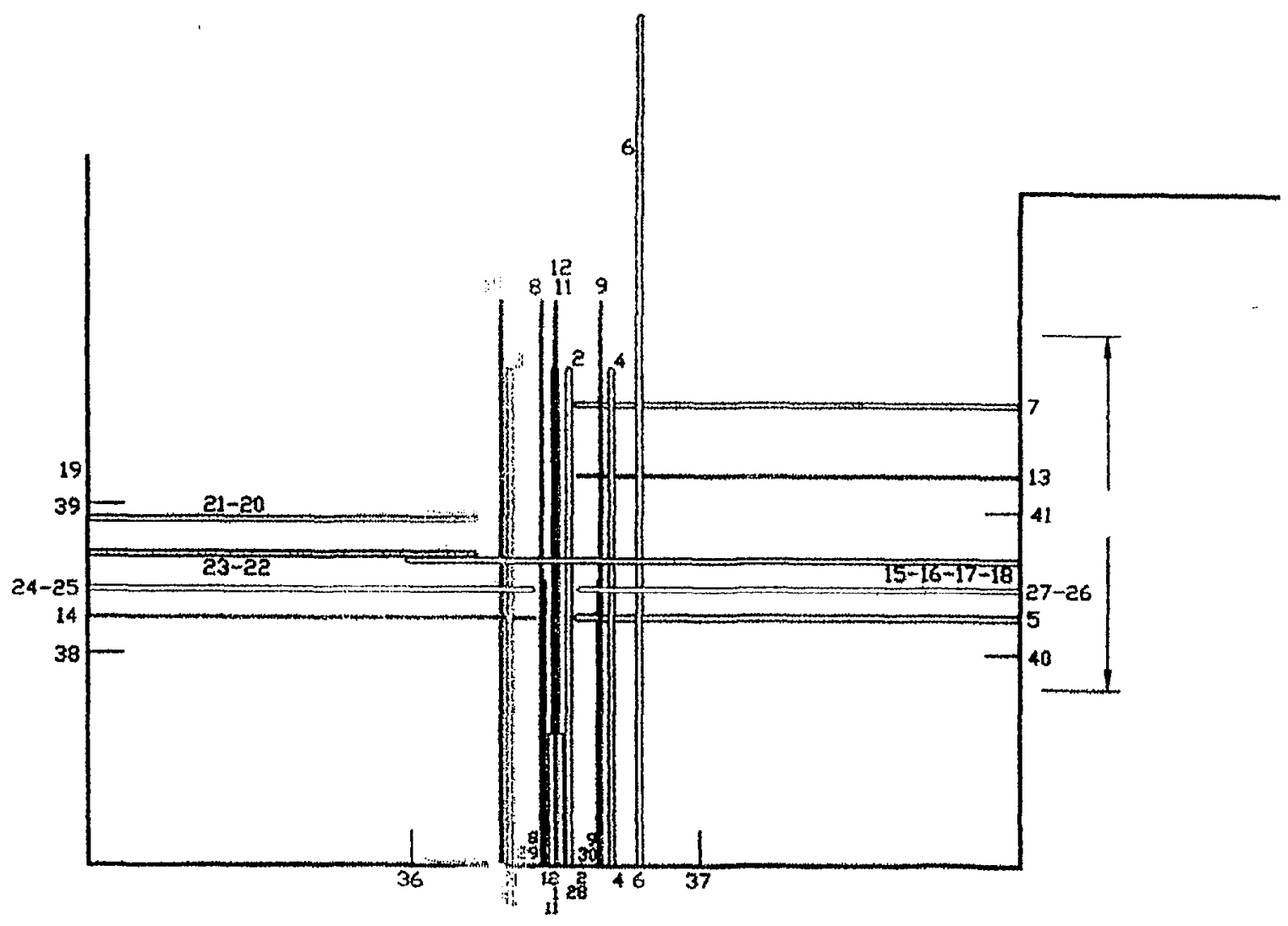

Figure 1(b). Plain view of the borehole layout of the Single Heater Test. See CRWMS MaO (1996a) for description of the boreholes. The boreholes are identified by the numbers. The colors do not have significant meaning. 


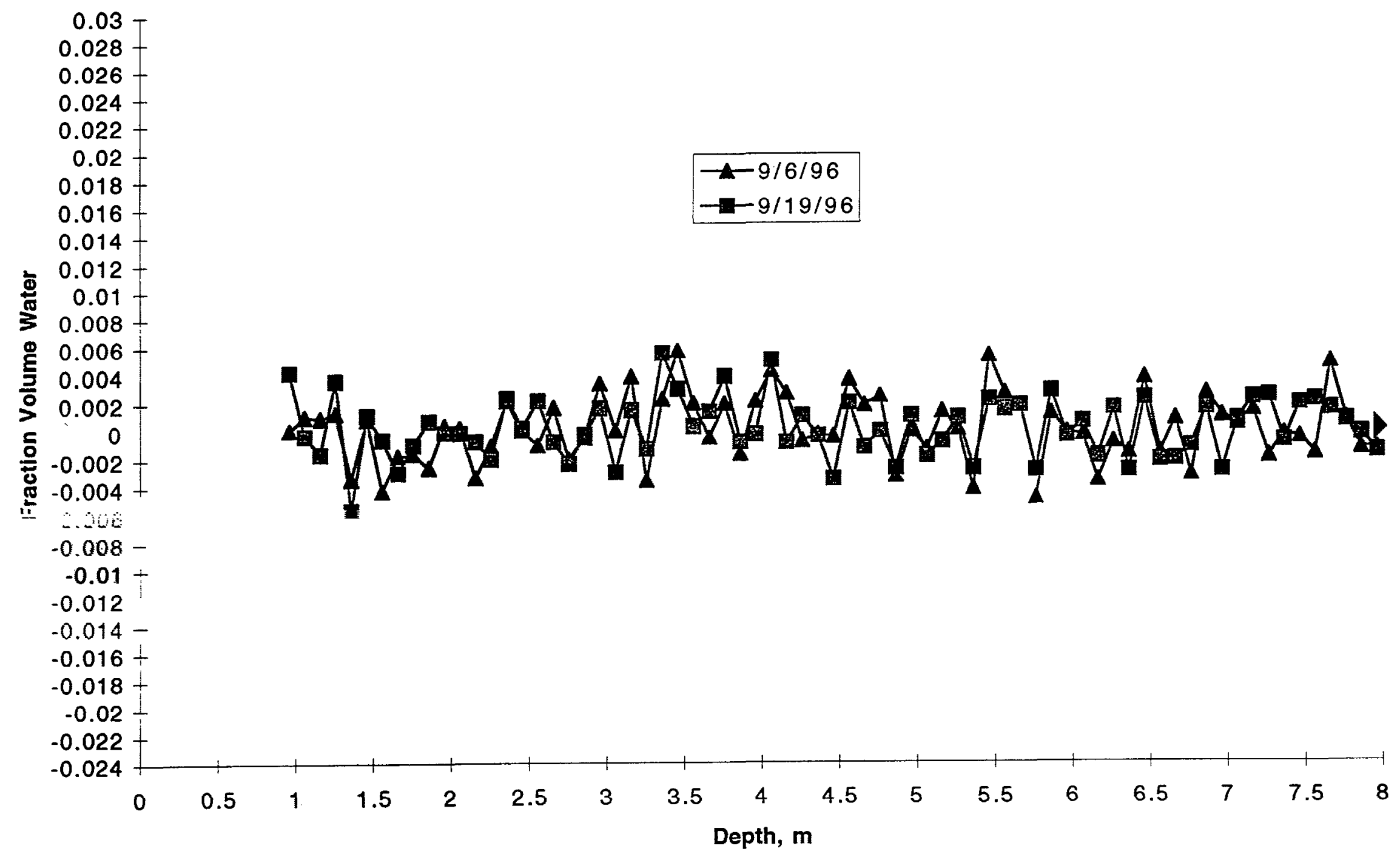

Figure 2. Difference fraction volume water content in Hole\#15 as a function of depth from collar on 9/6/96 and 9/19/96. 


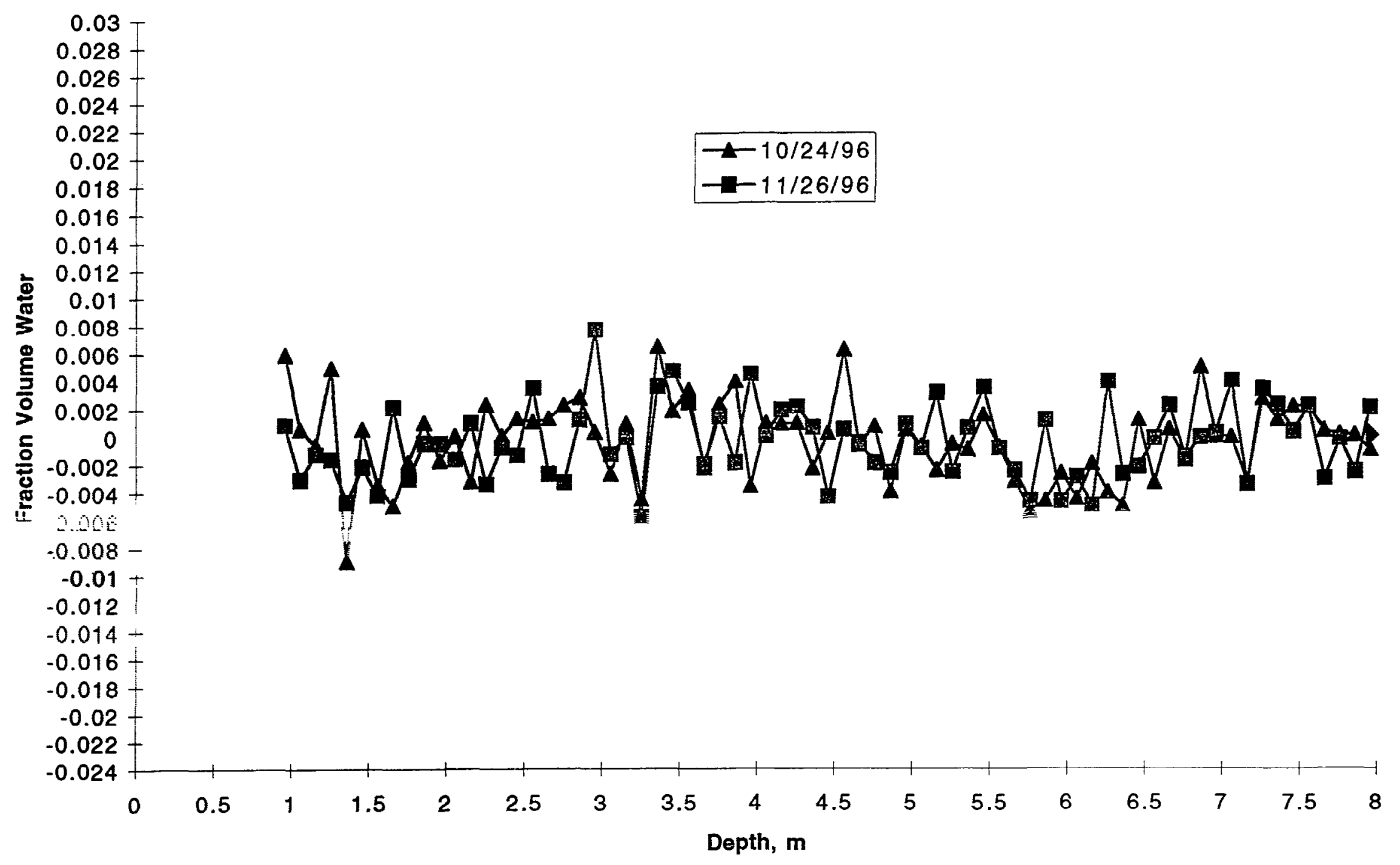

Figure 3. Difference fraction volume water content in Hole\#15 as a function of depth from collar on 10/24/96 and 11/26/96. 


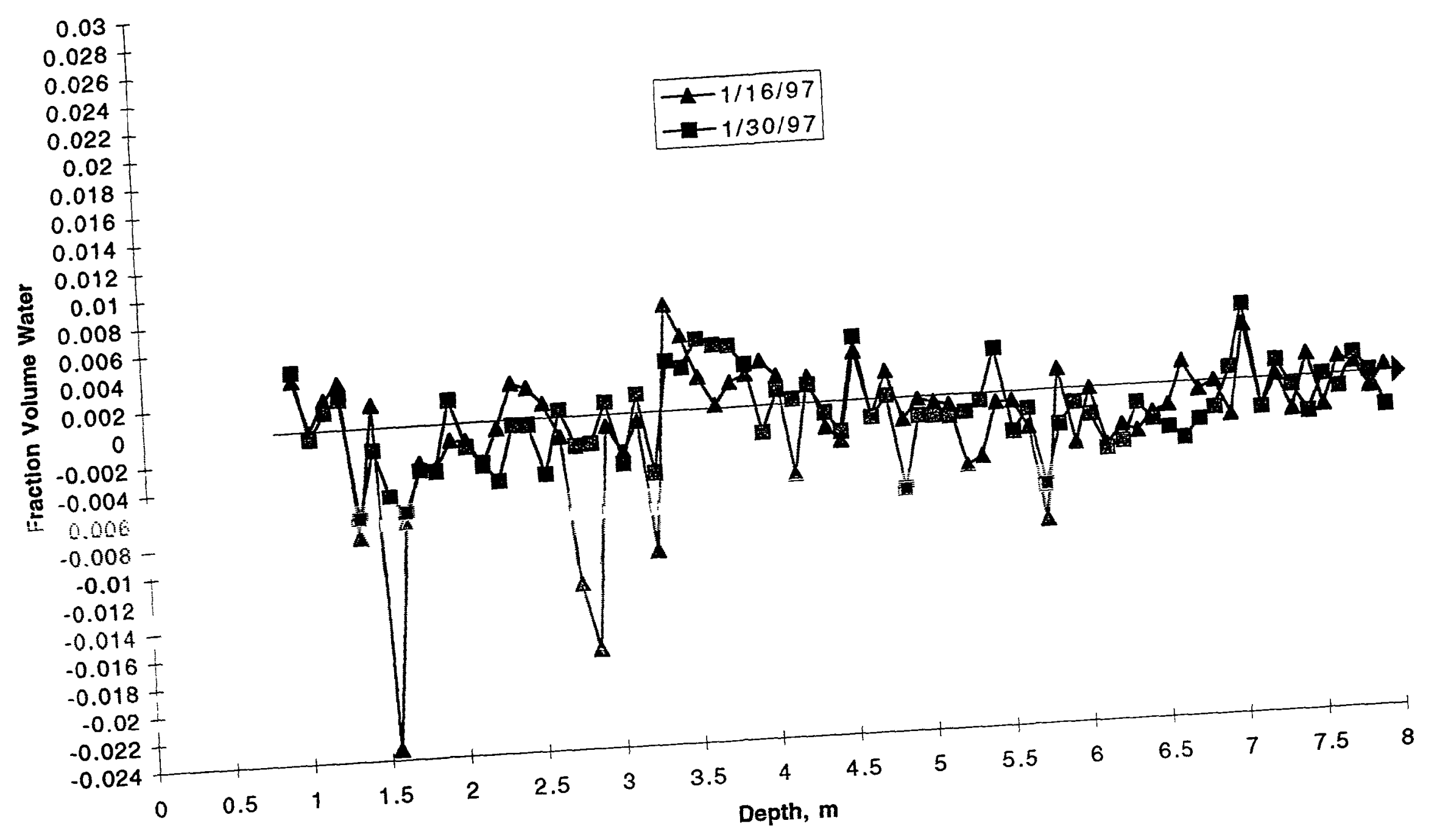

Figure 4. Difference fraction volume water content in Hole\#15
$1 / 30 / 97$. 


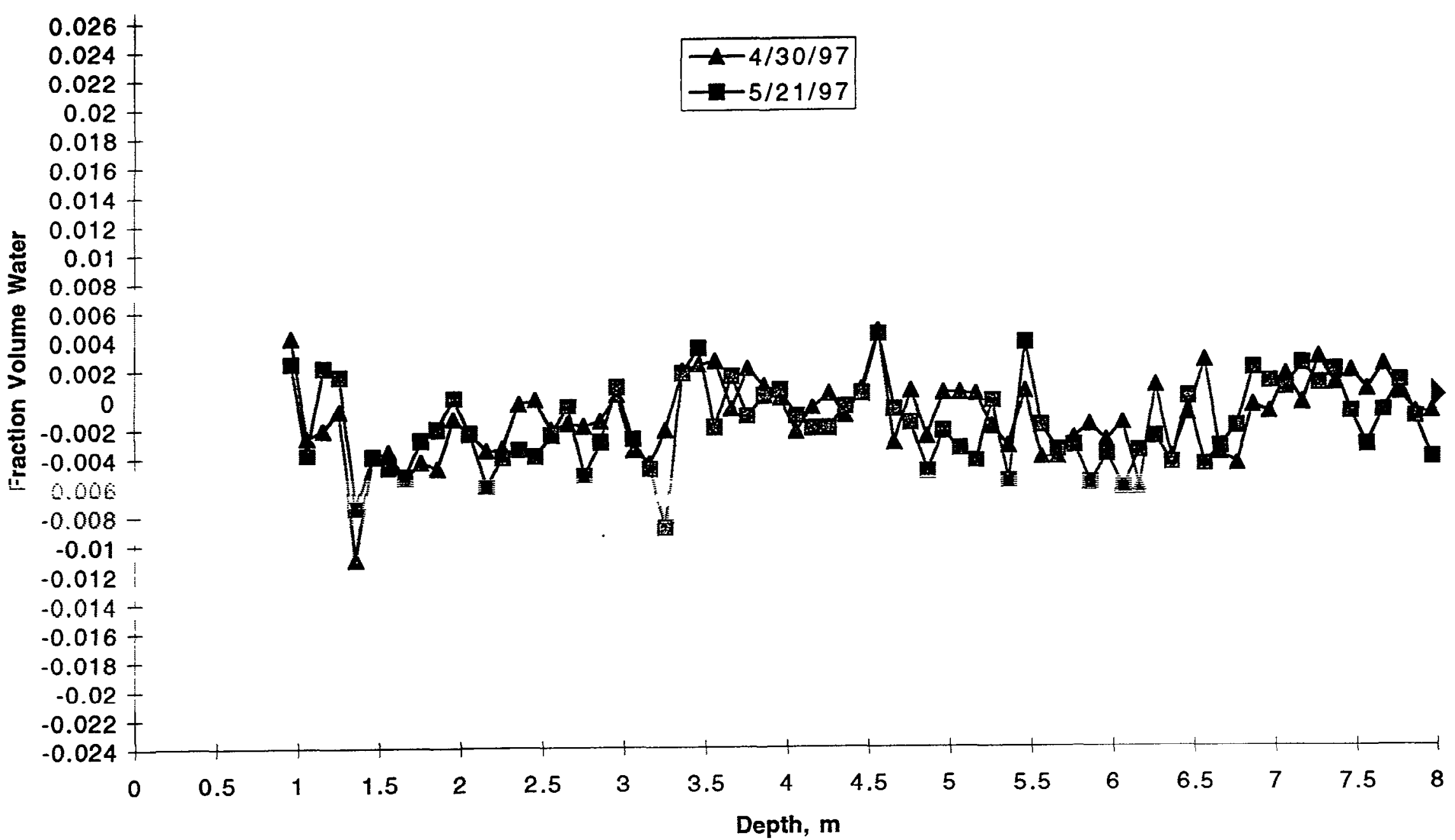

Figure 6. Difference fraction volume water content in Hole\#15 as a function of depth from collar on 4/30/97 and $5 / 21 / 97$. 


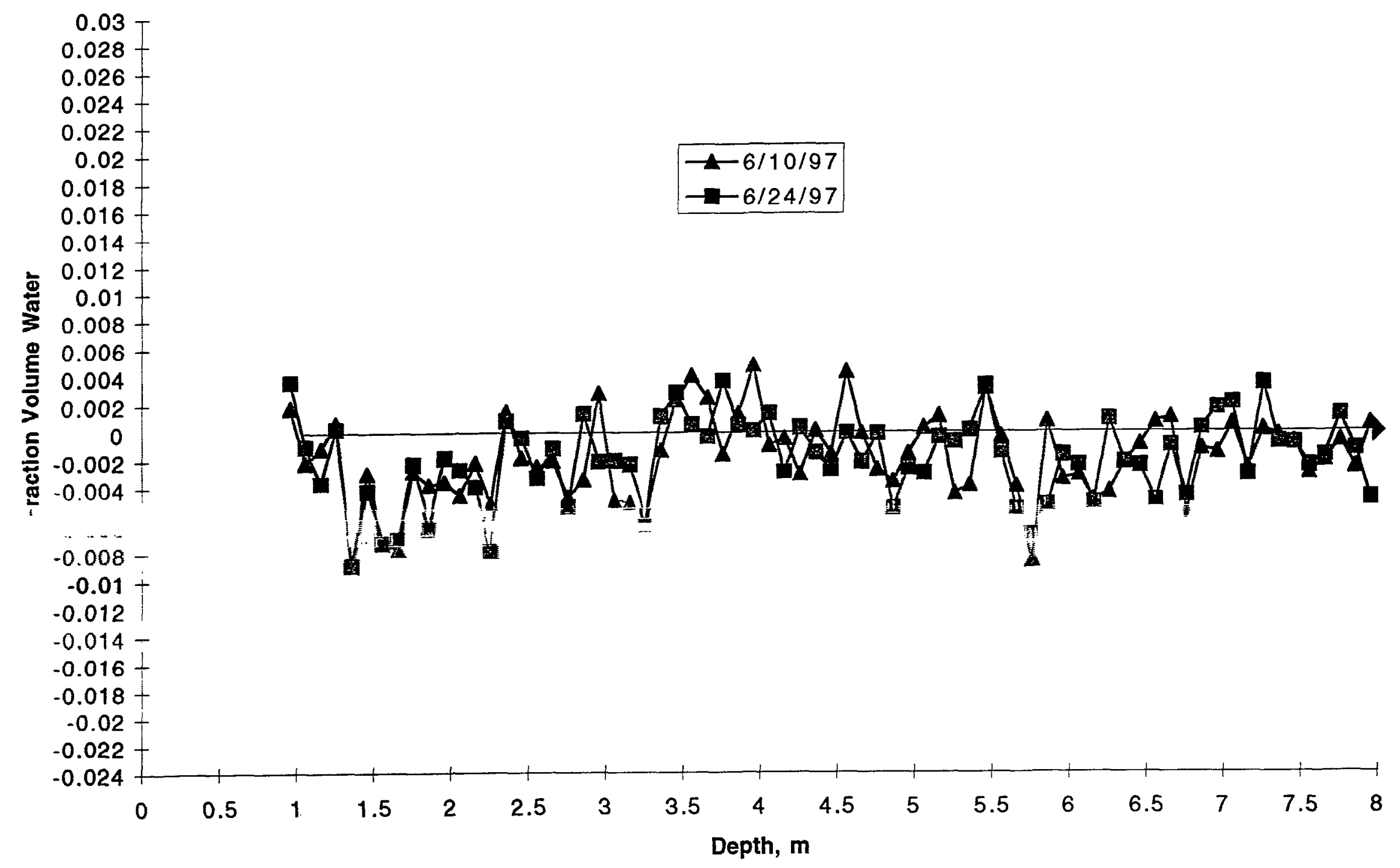

Figure 7. Difference fraction volume water content in Hole\#15 as a function of depth from collar on 6/10/97 and 6/24/97. 


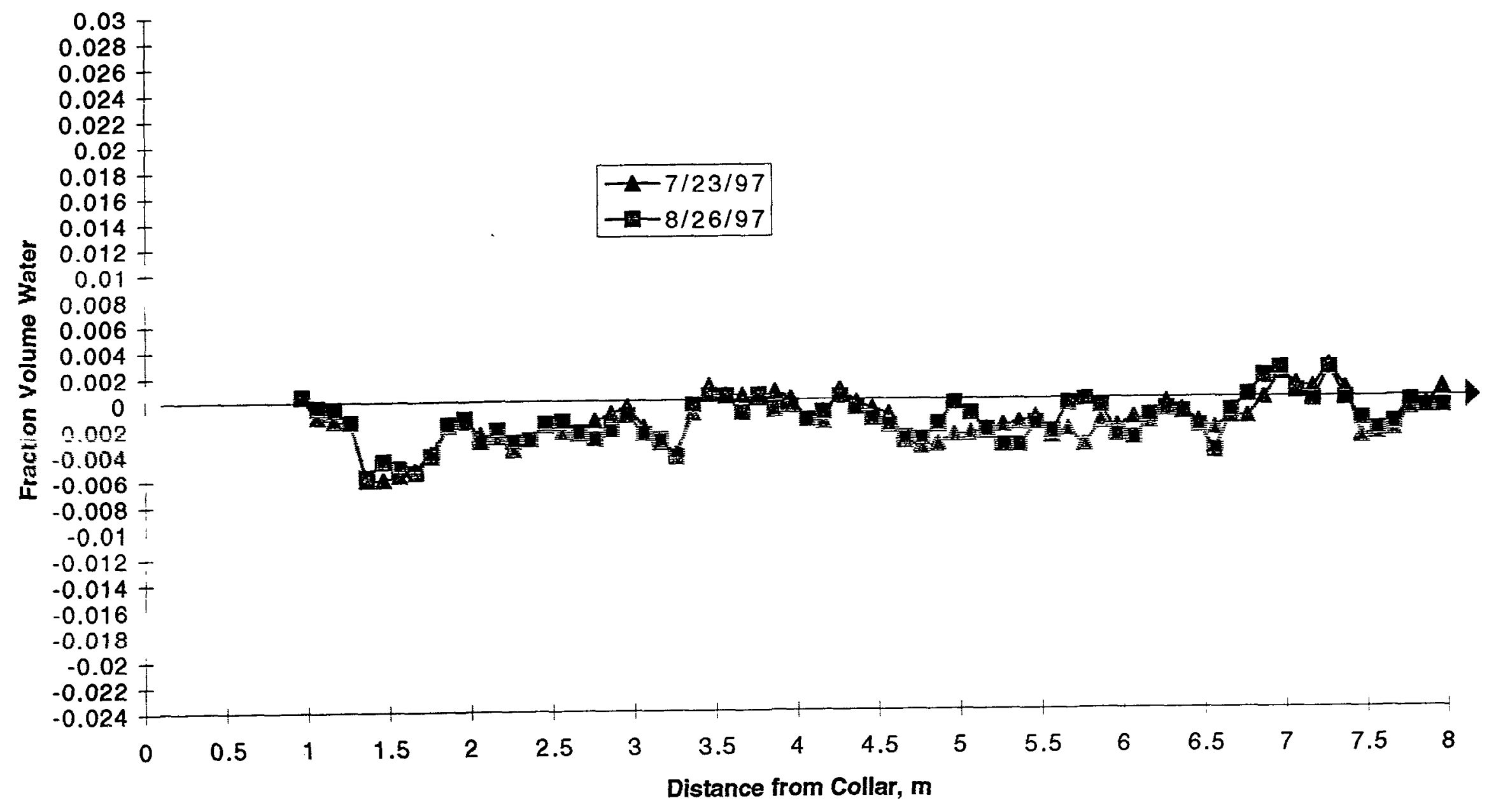

Figure 8. Smoothed difference fraction volume water content in Hole\#15 as a function of depth from collar on $7 / 23 / 97$ and $8 / 26 / 97$. 


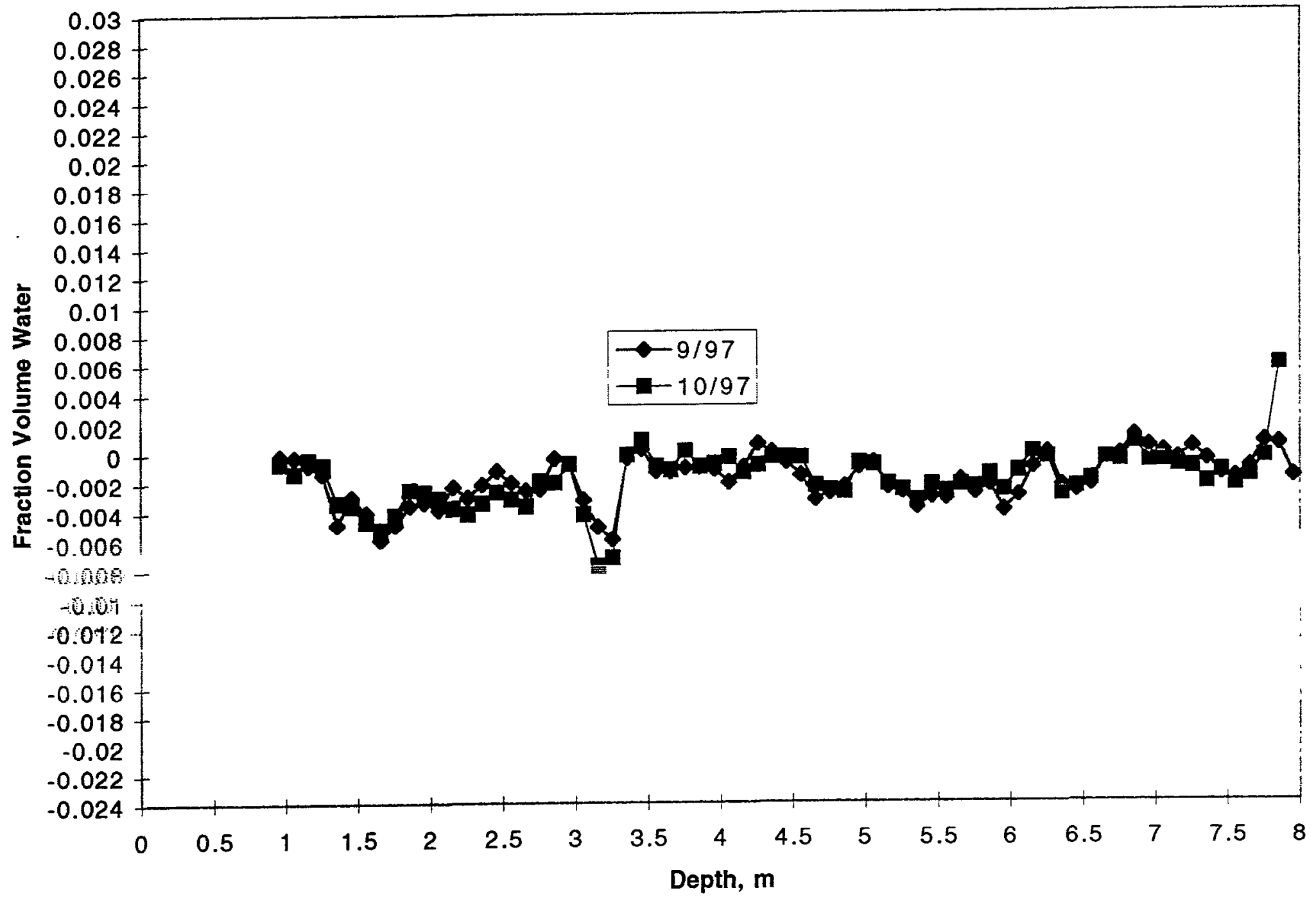

Figure 9. Smoothed difference fraction volume water content in Hole\#15 as a function of depth from collar on 9/97 and 10/97. 


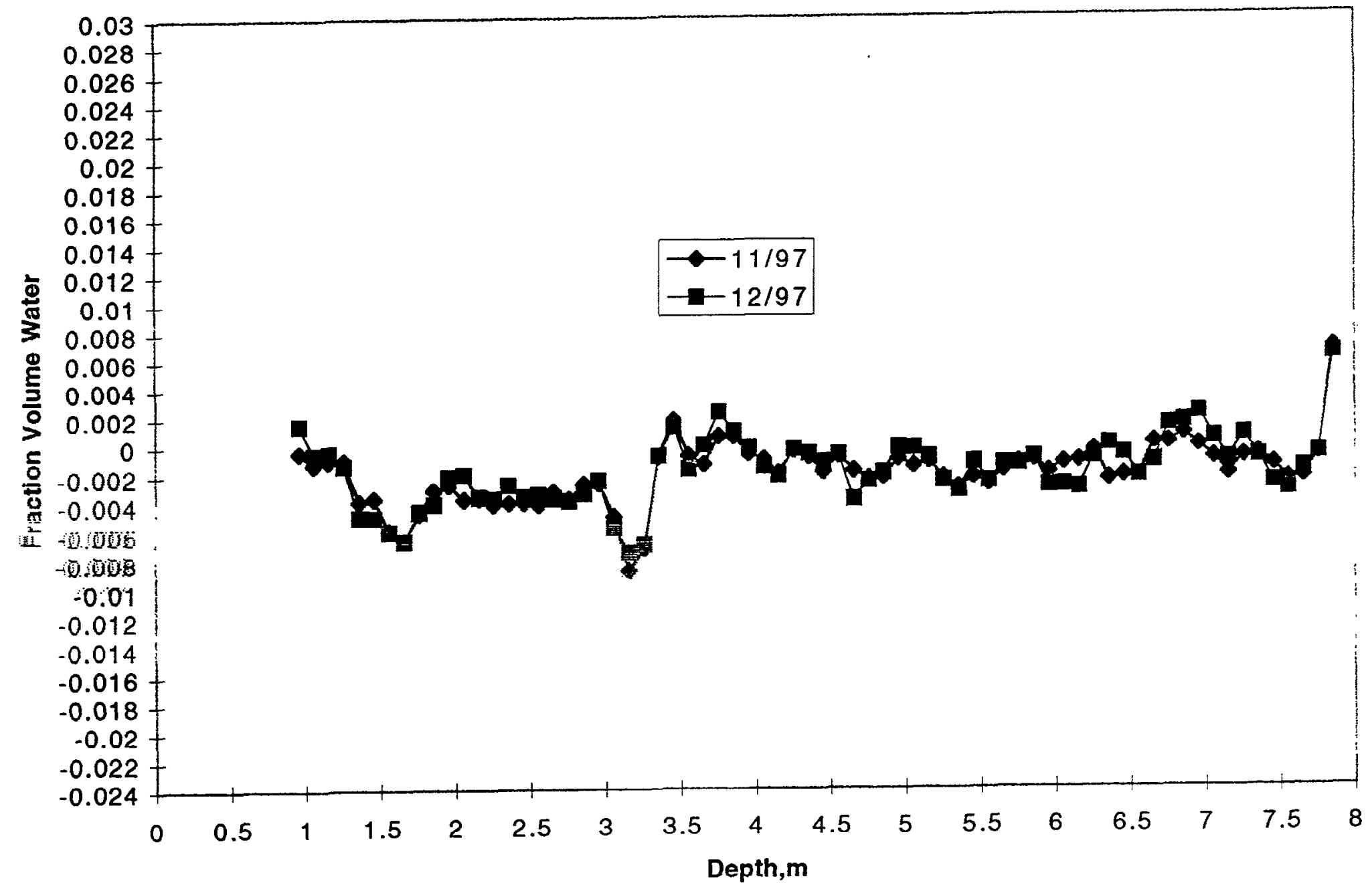

Figure 10. Smoothed difference fraction volume water content in Hole\#15 as a function of depth from collar on 11/97 and 12/97. 


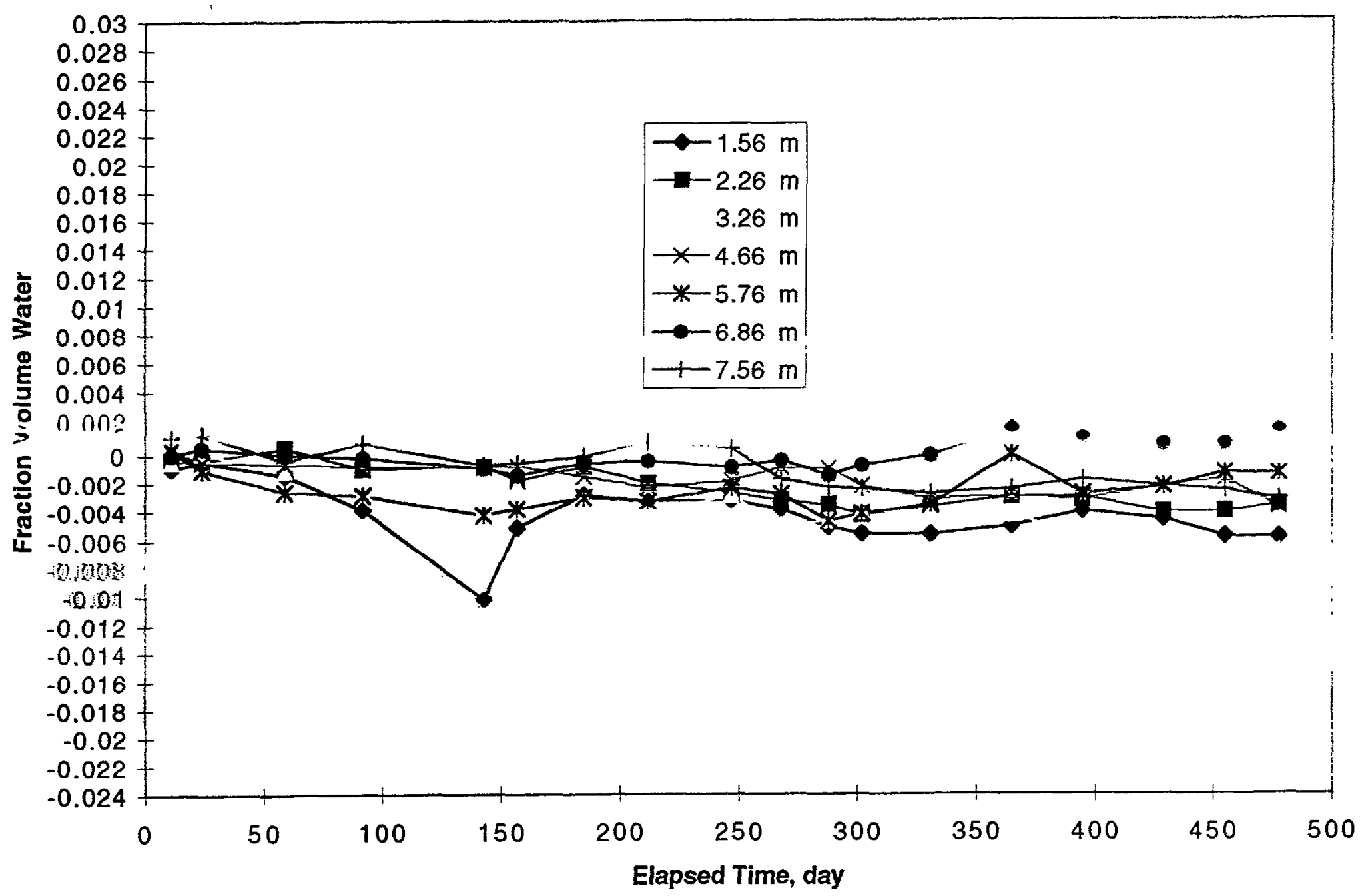

Figure 11. Smoothed difference fraction volume water content at various depths in Hole\#15 as a function of time. 


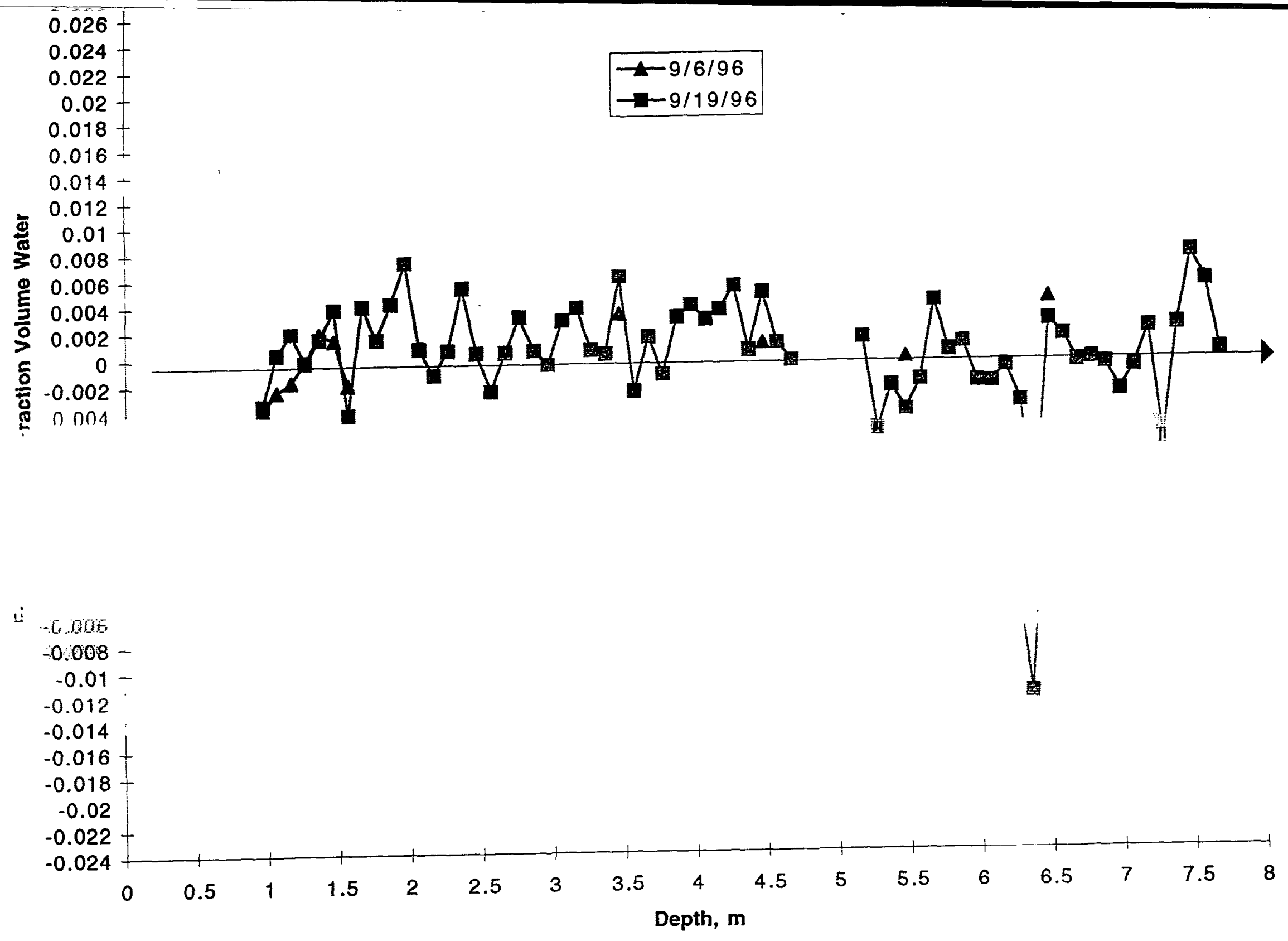

Figure 12. Difference fraction volume water content in Hole\#17 as a function of depth from collar on 9/6/96 and 9/19/96. 


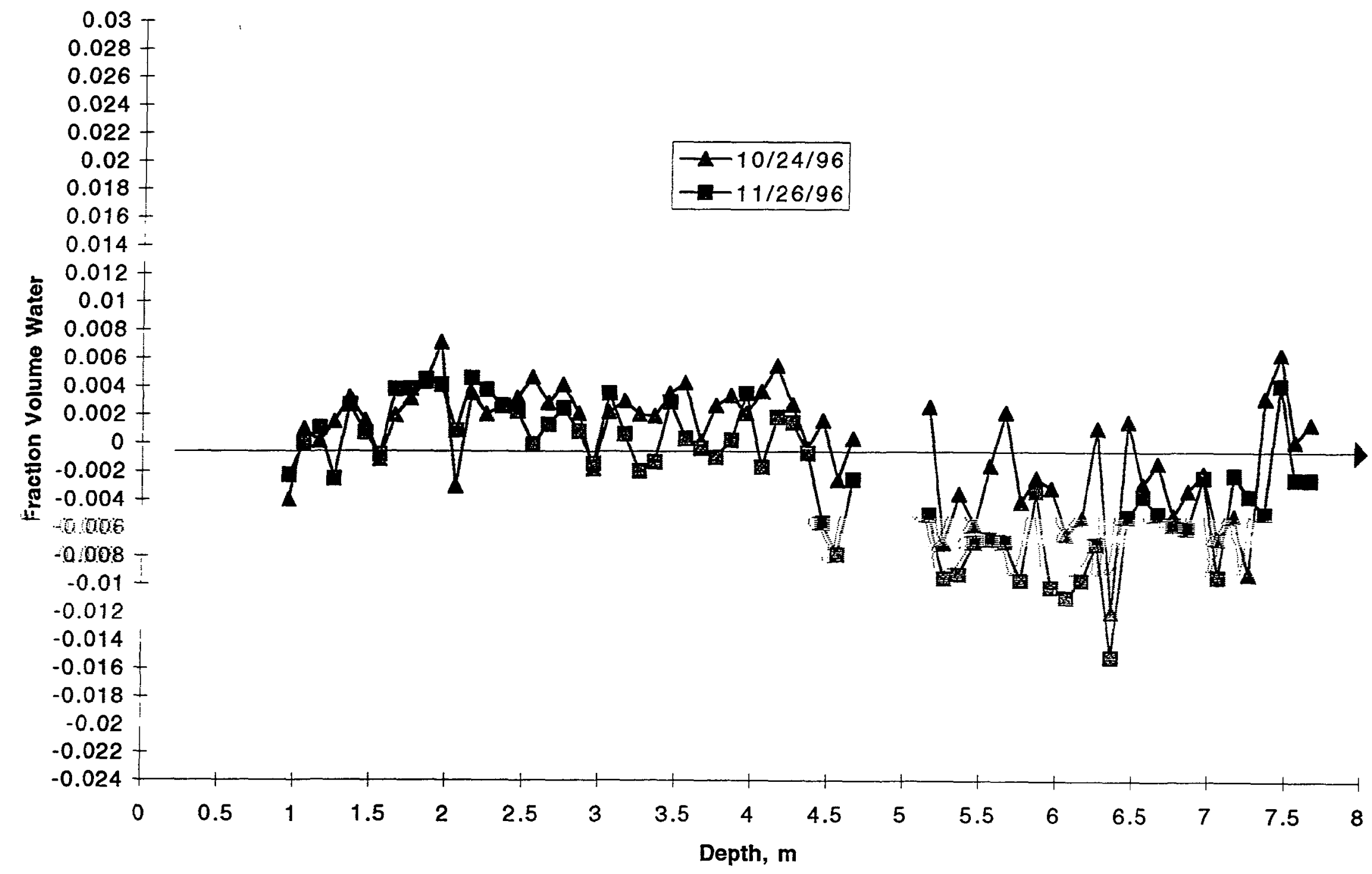

Figure 13. Difference fraction volume water content in Hole\#17 as a function of depth from collar on 10/24/96 and 11/26/96. 


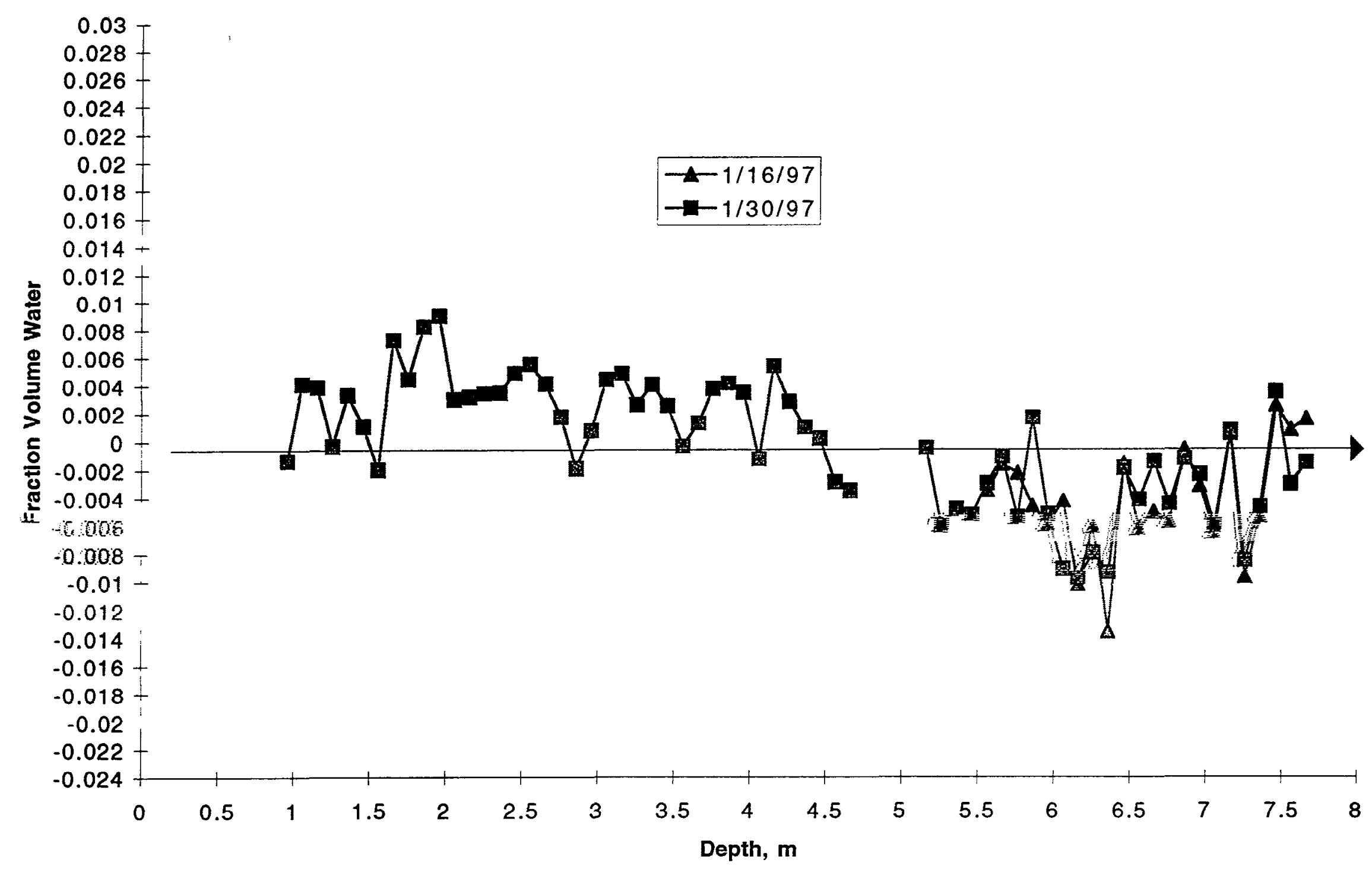

Figure 14. Difference fraction volume water content in Hole\#17 as a function of depth from collar on 1/16/97 and $1 / 30 / 97$. 


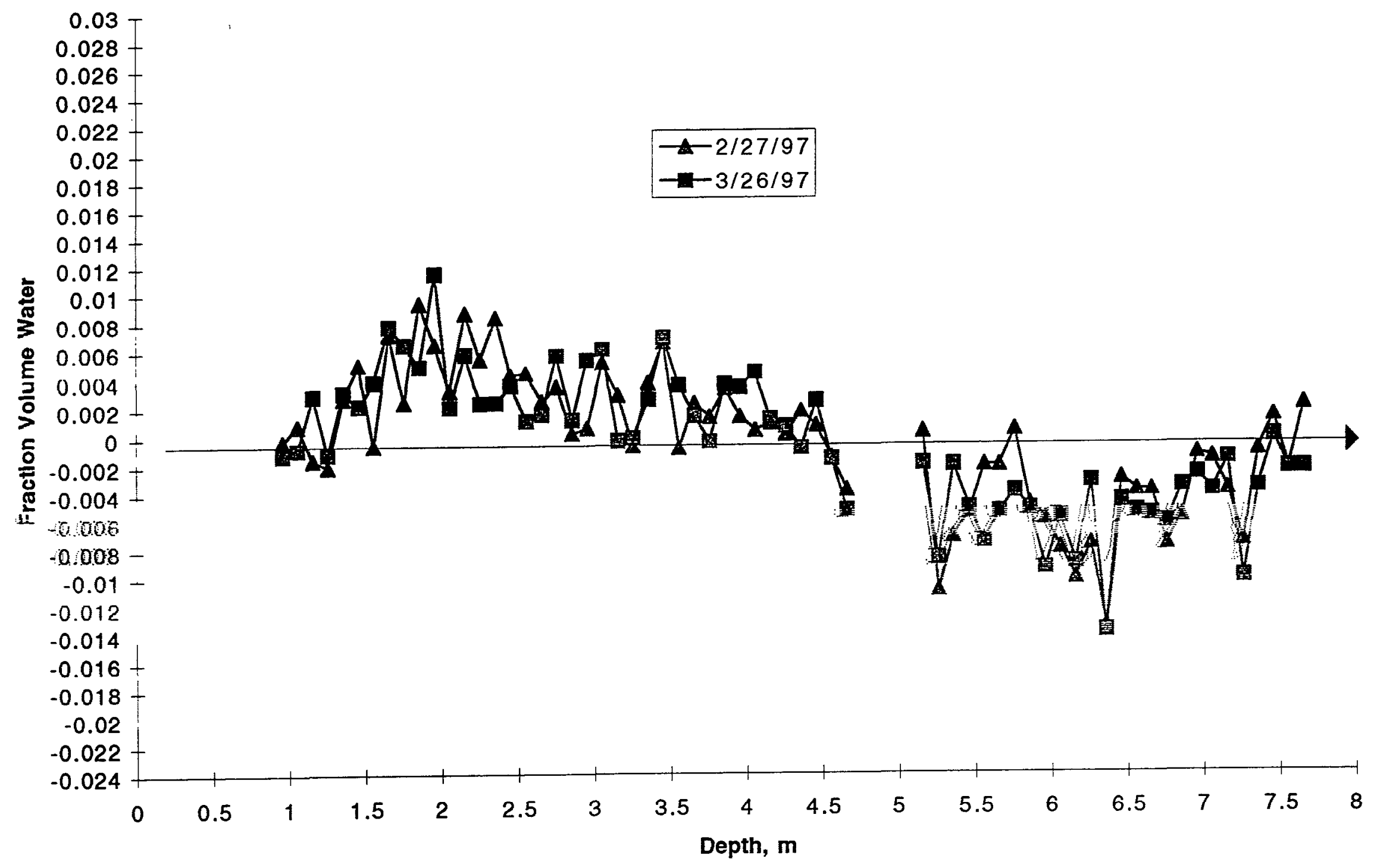
Figure 15. Difference fraction volume water content in Hole\#17 as a function of depth from collar on $2 / 27 / 97$ and
$3 / 26 / 97$. 


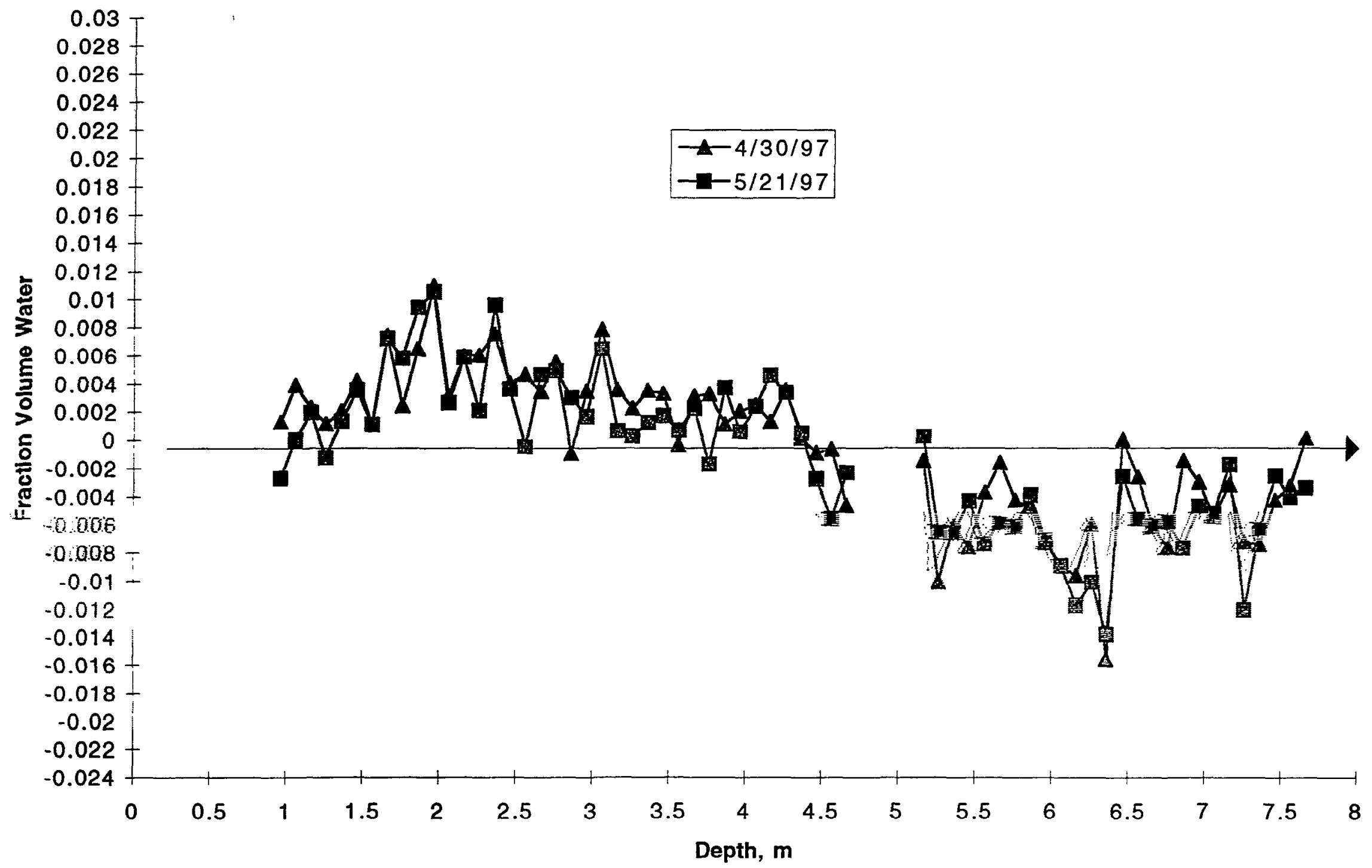

Figure 16. Difference fraction volume water content in Hole\#17 as a function of depth from collar on 4/30/97 and 5/21/97. 


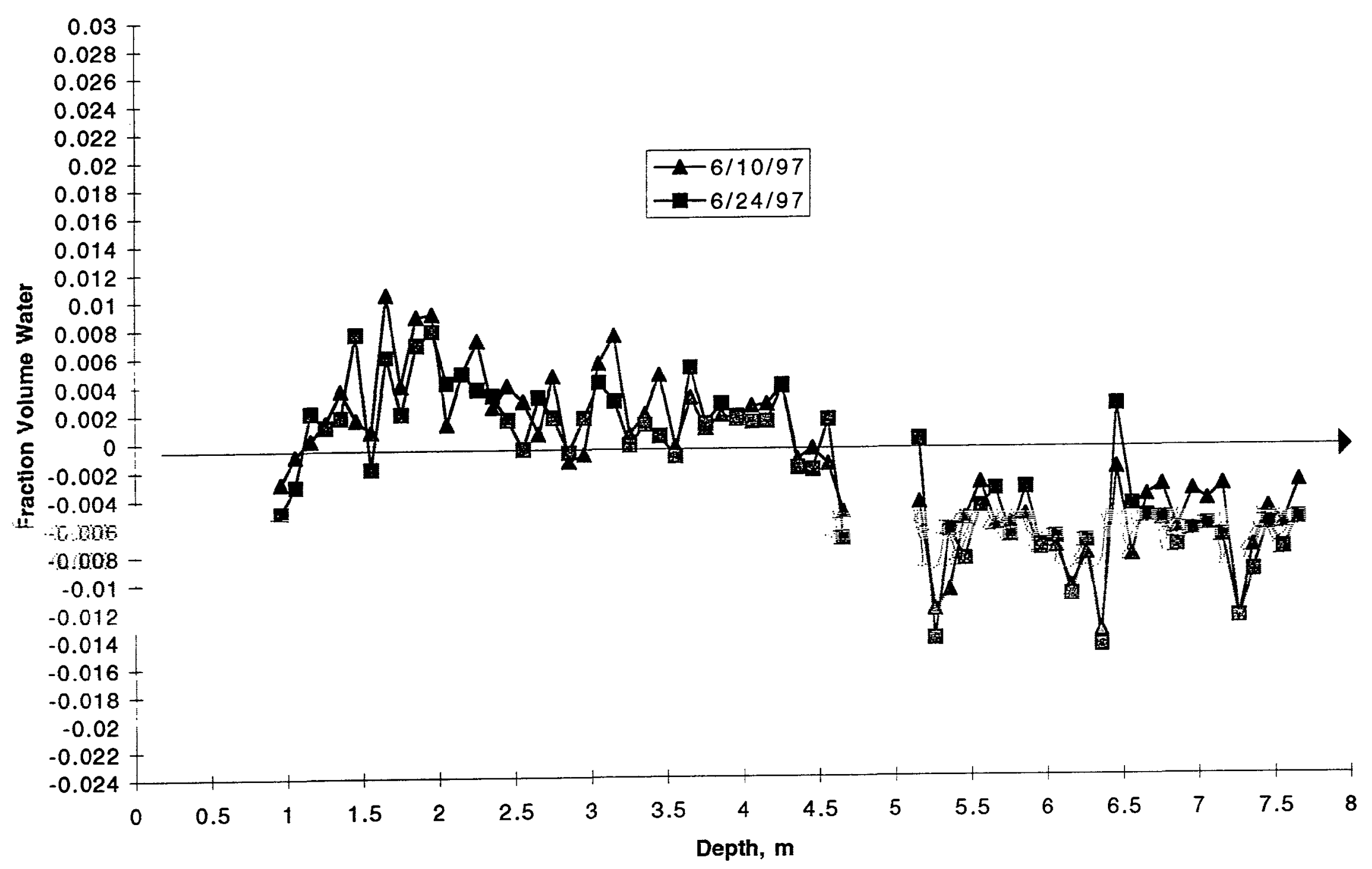

Figure 17. Difference fraction volume water content in Hole\#17 as a function of depth from collar on 6/10/97 and 6/24/97. 


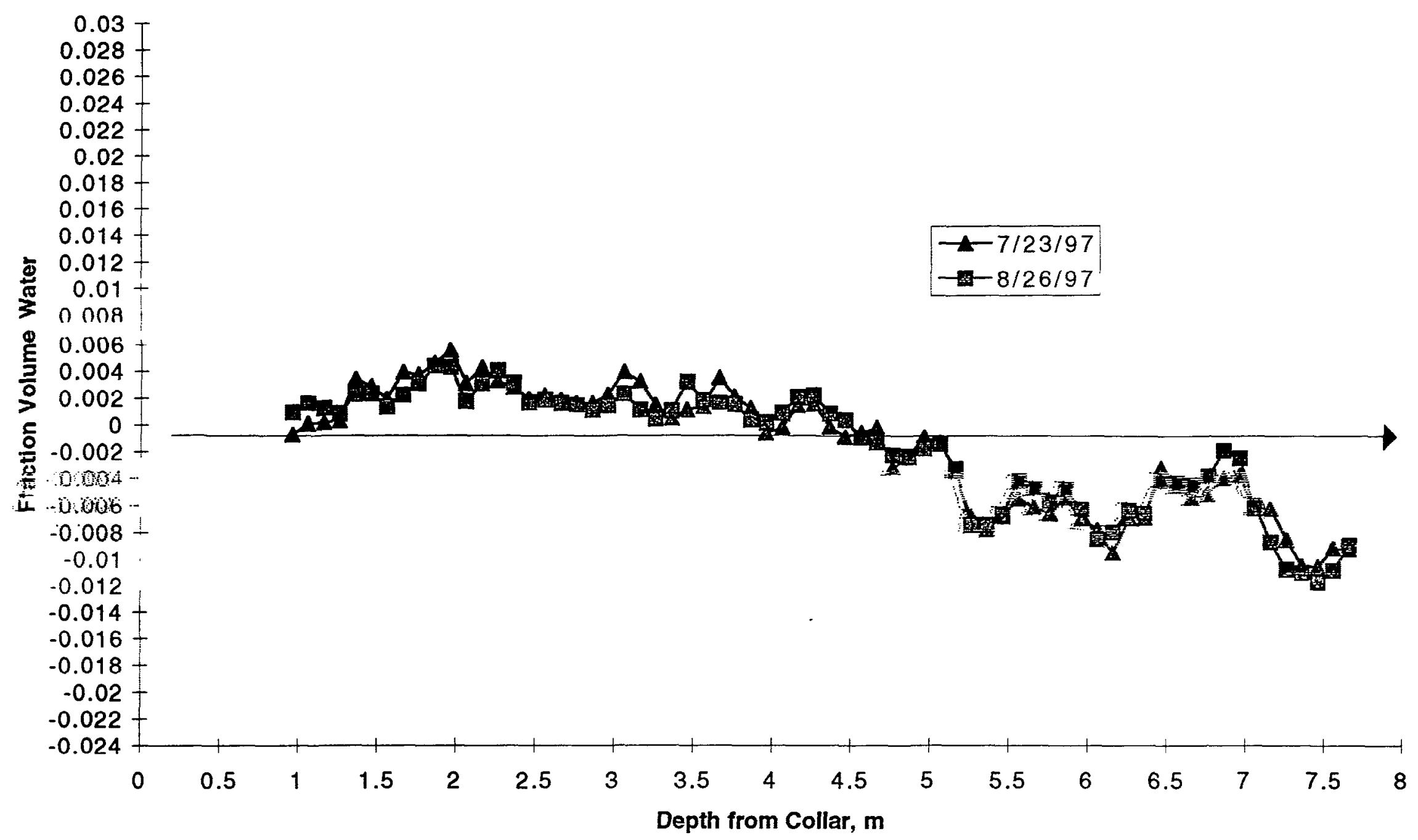

Figure 18. Smoothed difference fraction volume water content in Hole\#17 as a function of depth from collar on $7 / 23 / 97$ and $8 / 26 / 97$. 


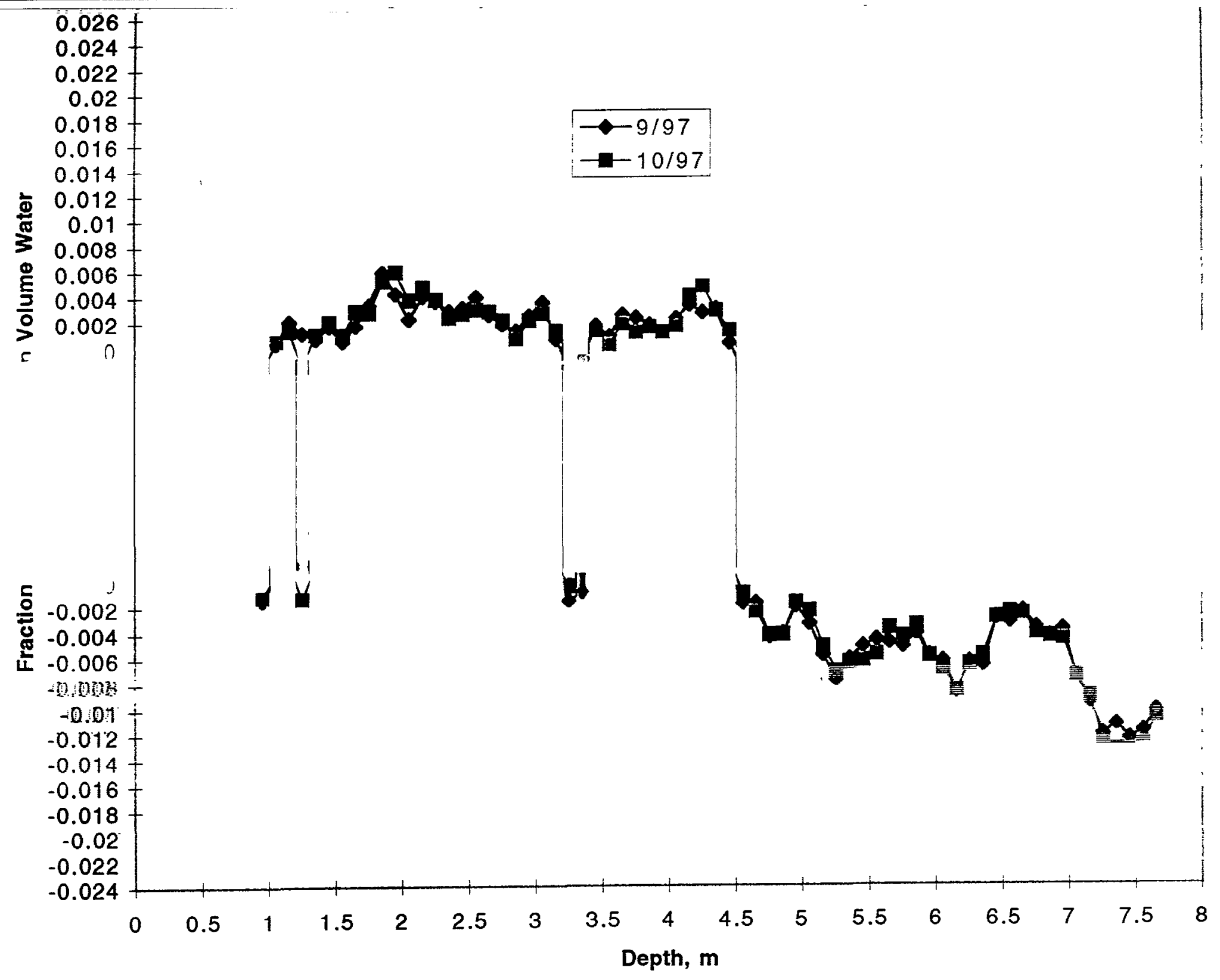

Figure 19. Smoothed fraction volume water content in Hole\#17 as a function of depth from collar on $9 / 97$ and $10 / 97$. 


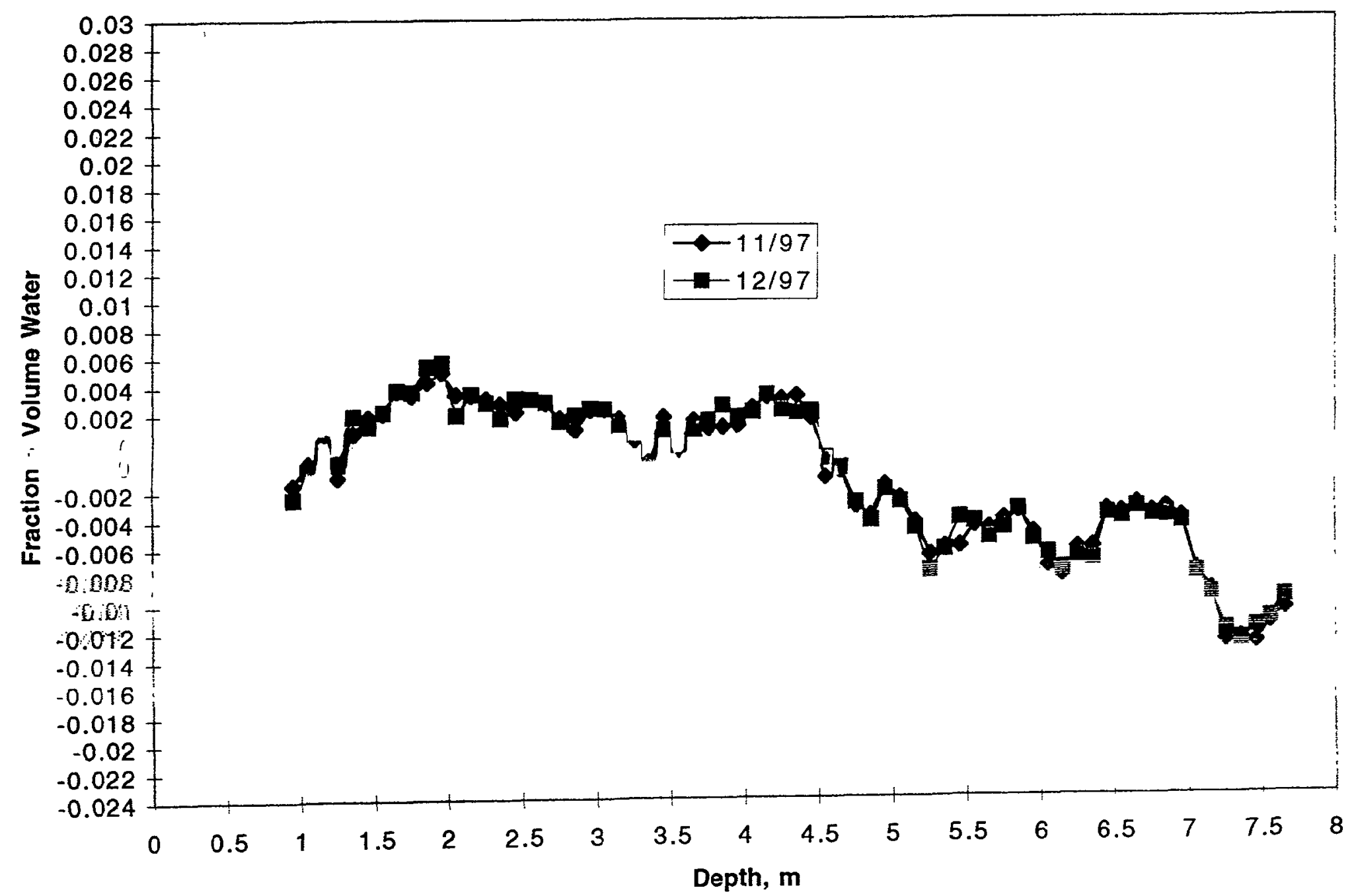

Figure 20. Smoothed difference volume water content in Hole\#17 as a functionof depth from collar on $11 / 97$ and $12 / 97$ 


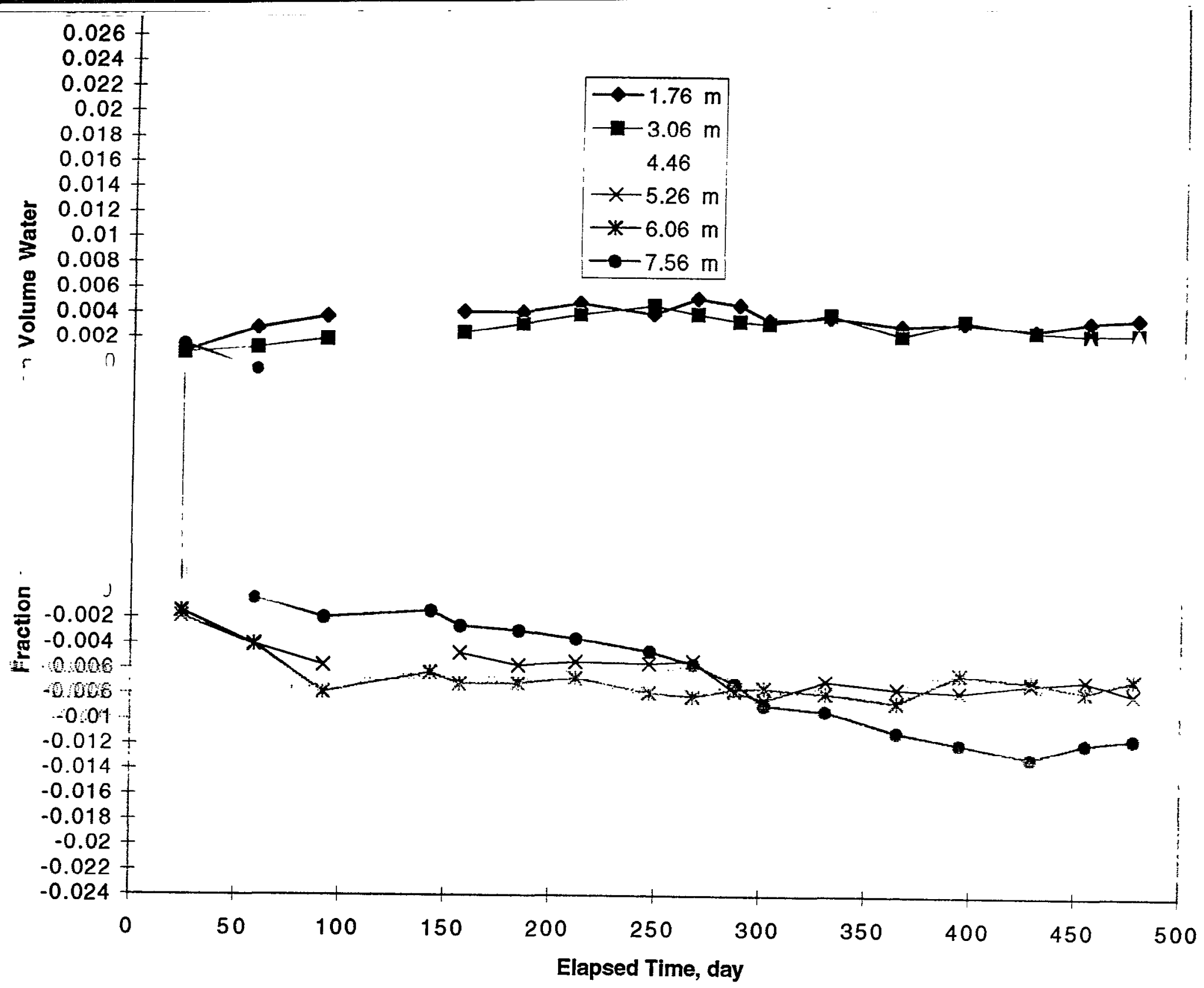

Figure 21. Smoothed difference fraction volume water content at various depths in Hole\#17 as a function of time 


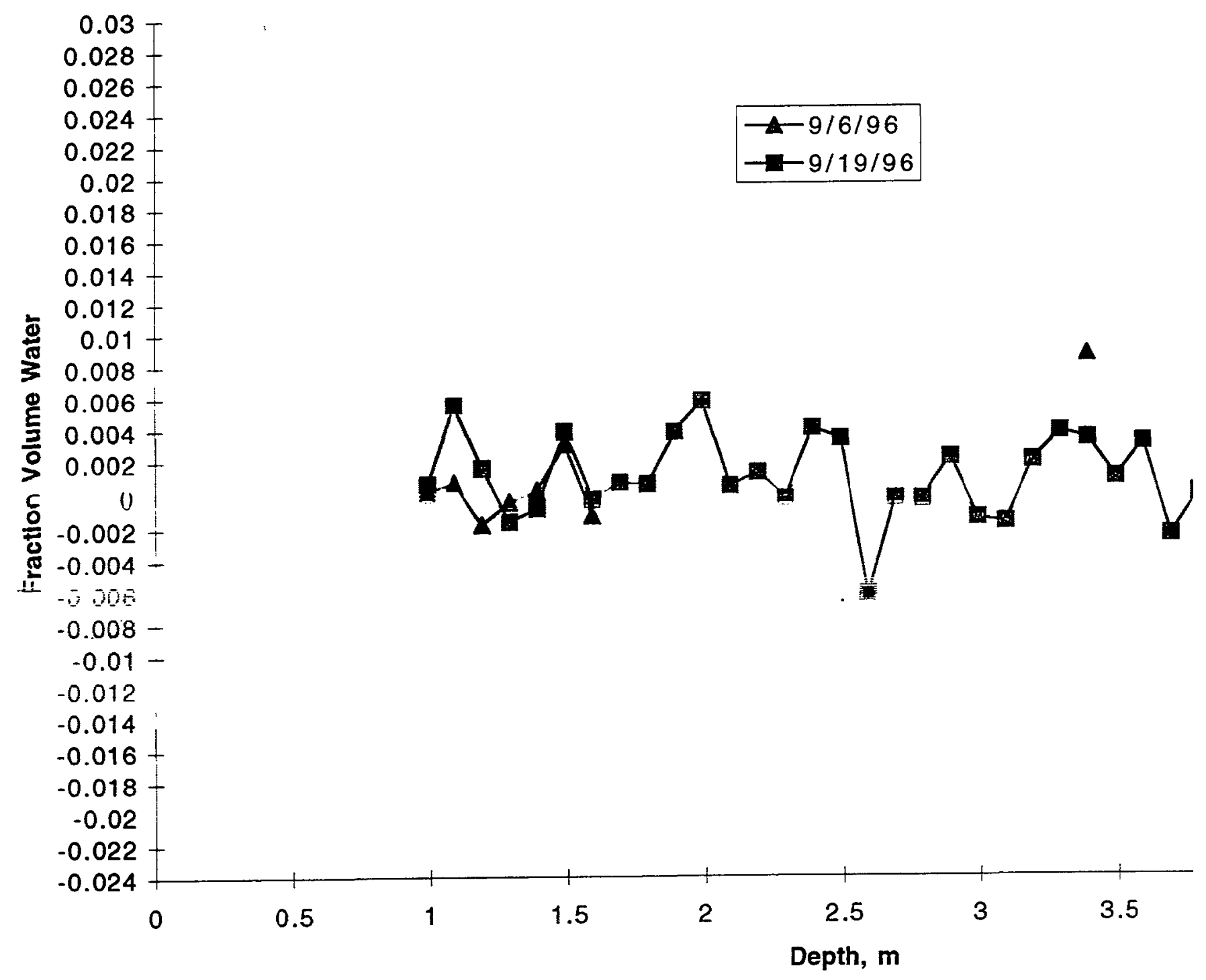

Figure 22. Difference fraction volume water content in Hole\#22 as a function of depth 9/19/96. 


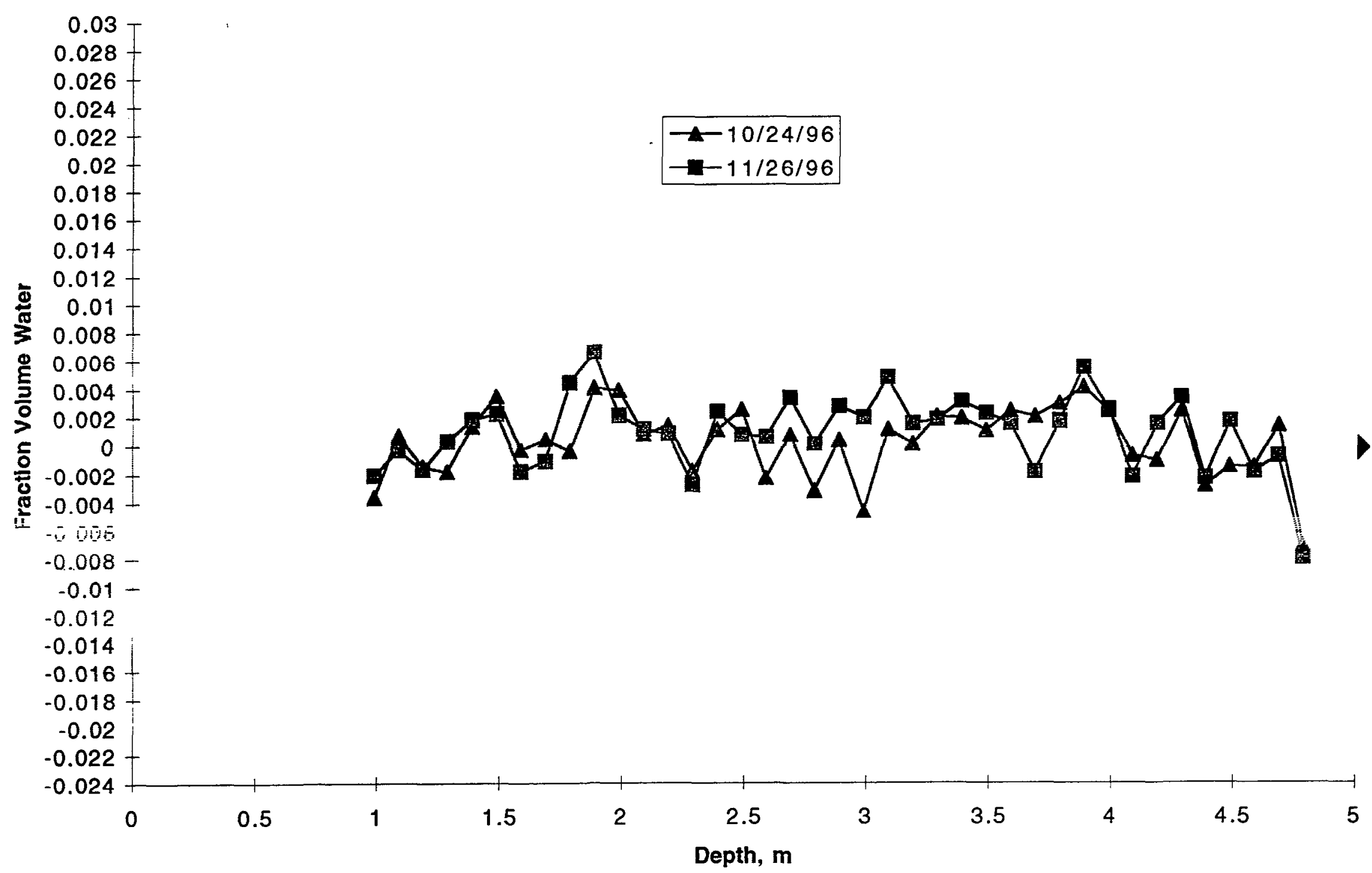

Figure 23. Difference fraction volume water content in Hole\#22 as a function of depth from collar on 10/24/96 and $11 / 26 / 96$. 


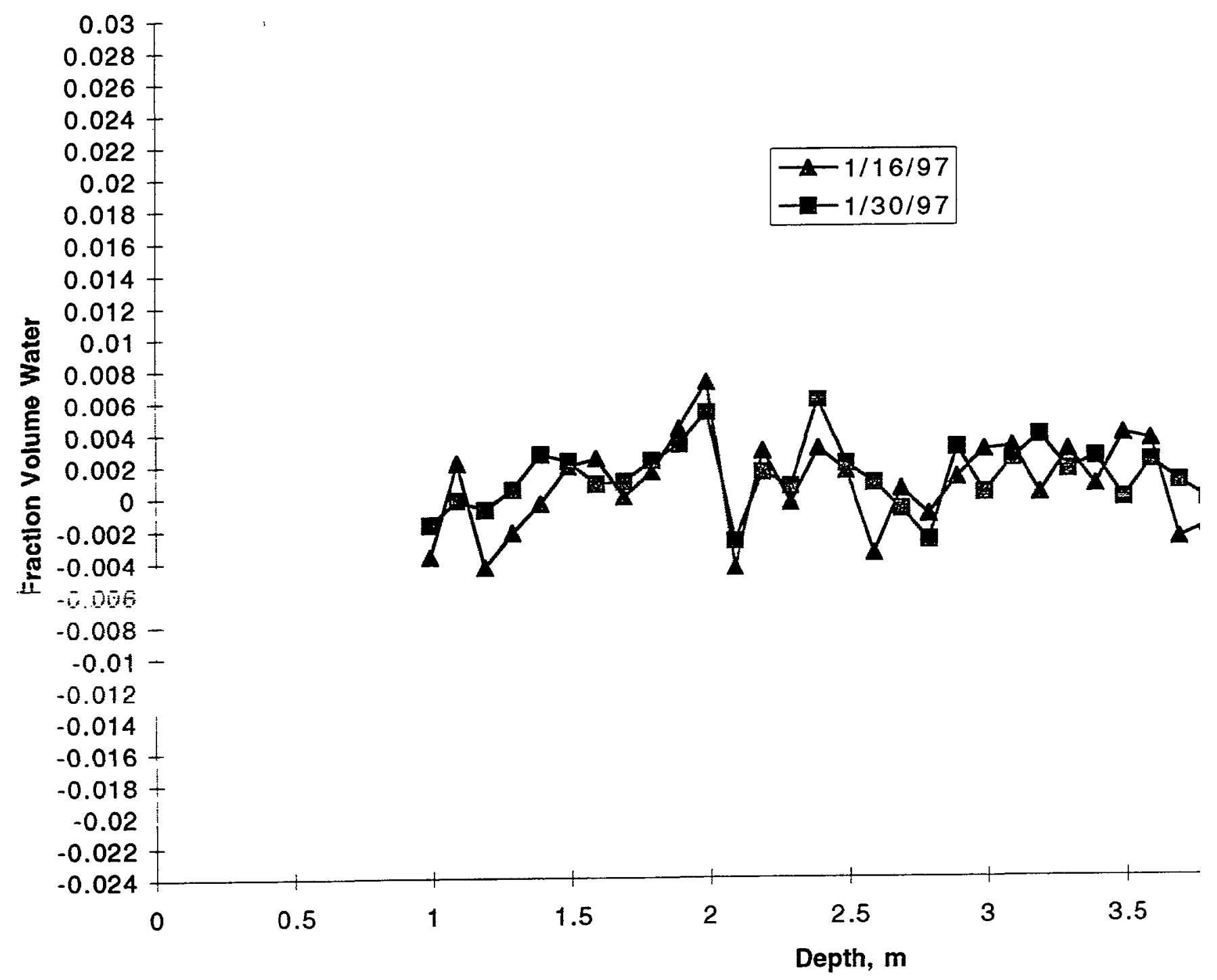

Figure 24. Difference fraction volume water content in Hole\#22 as a function of depth 1/30/97. 


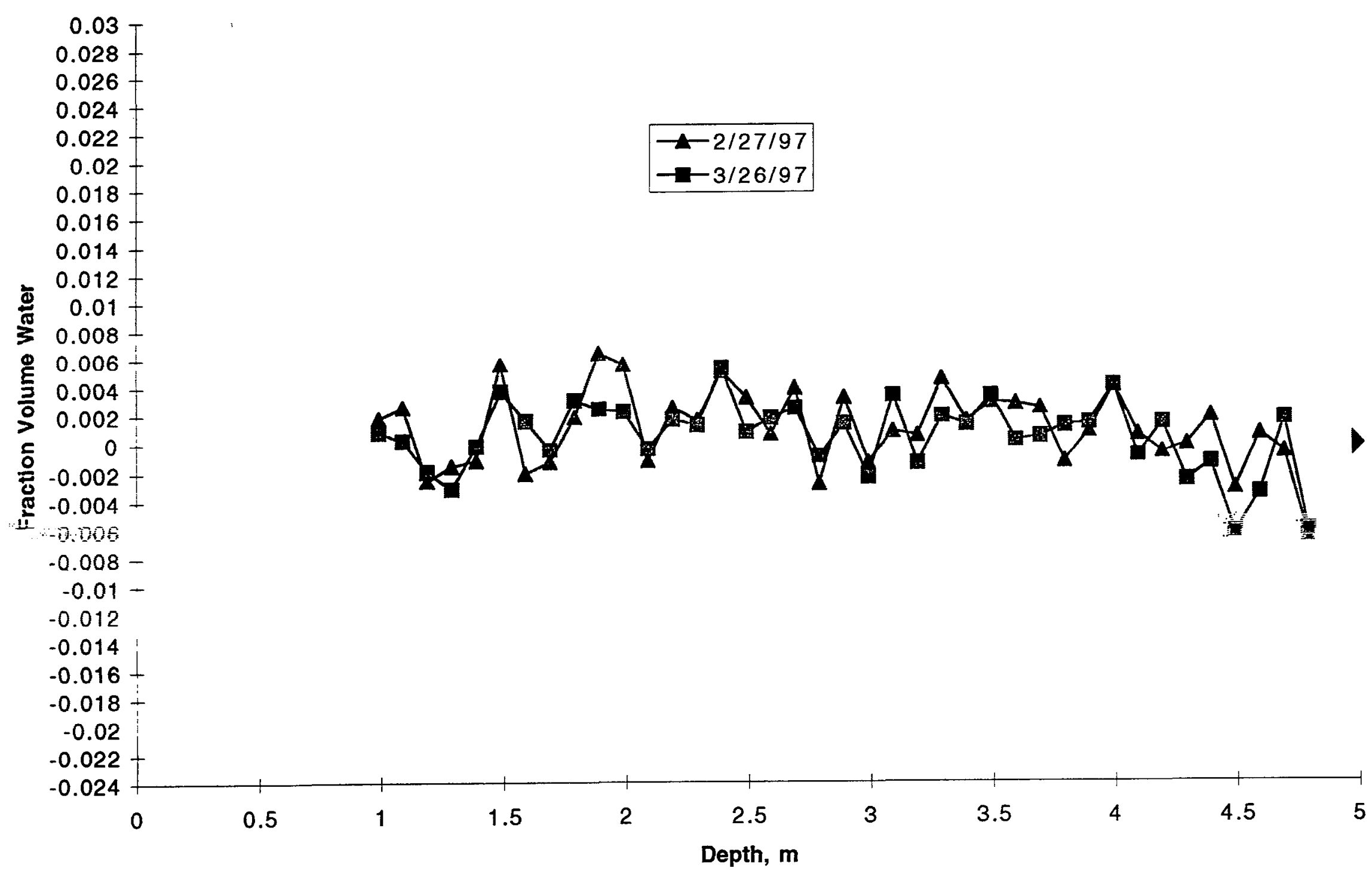

Figure 25. Difference fraction volume water content in Hole\#22 as a function of depth from collar on 2/27/97 and $3 / 26 / 97$. 


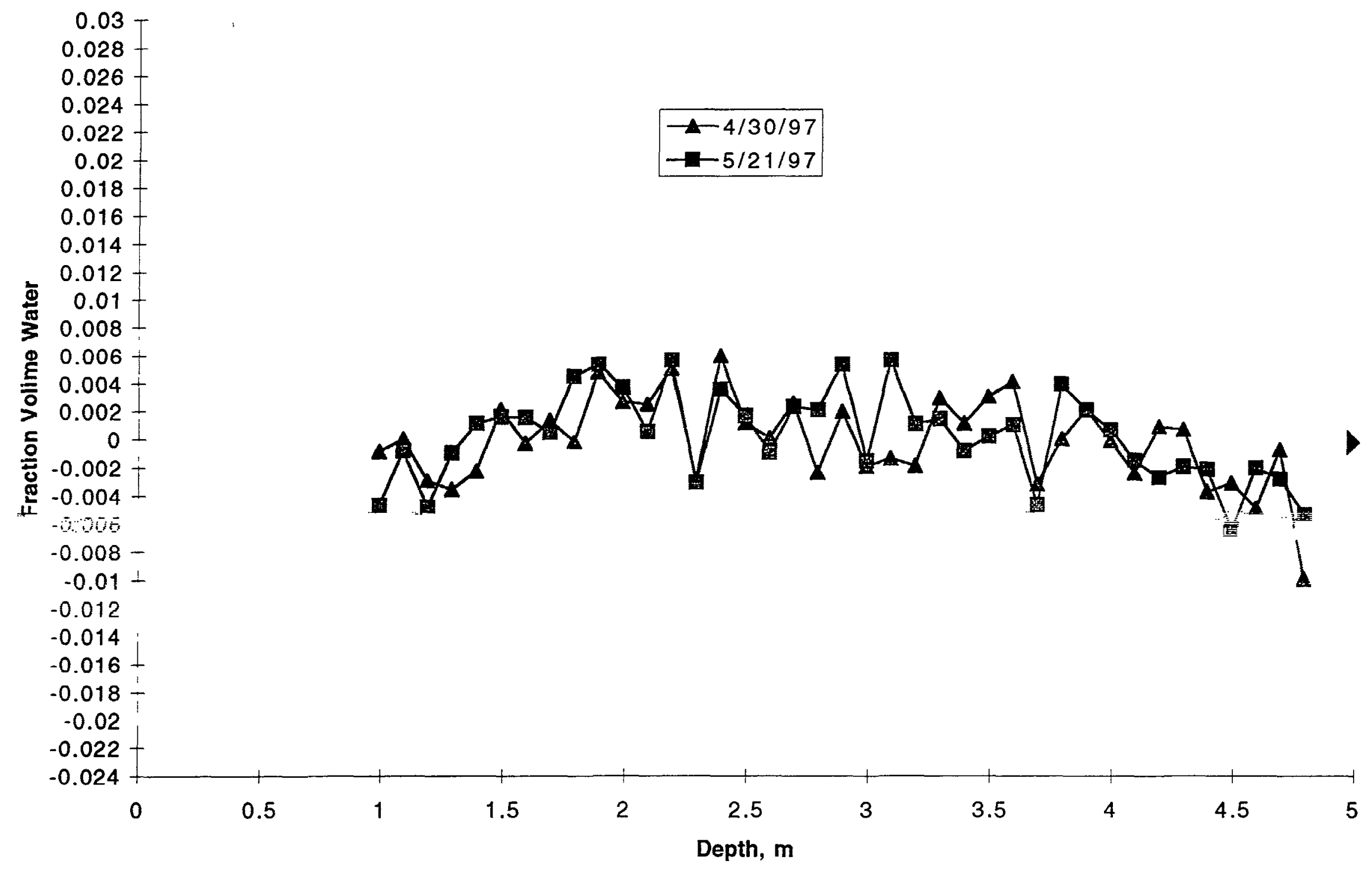

Figure 26. Difference fraction volume water content in Hole\#22 as a function of depth from collar on 4/30/97 and $5 / 21 / 97$. 


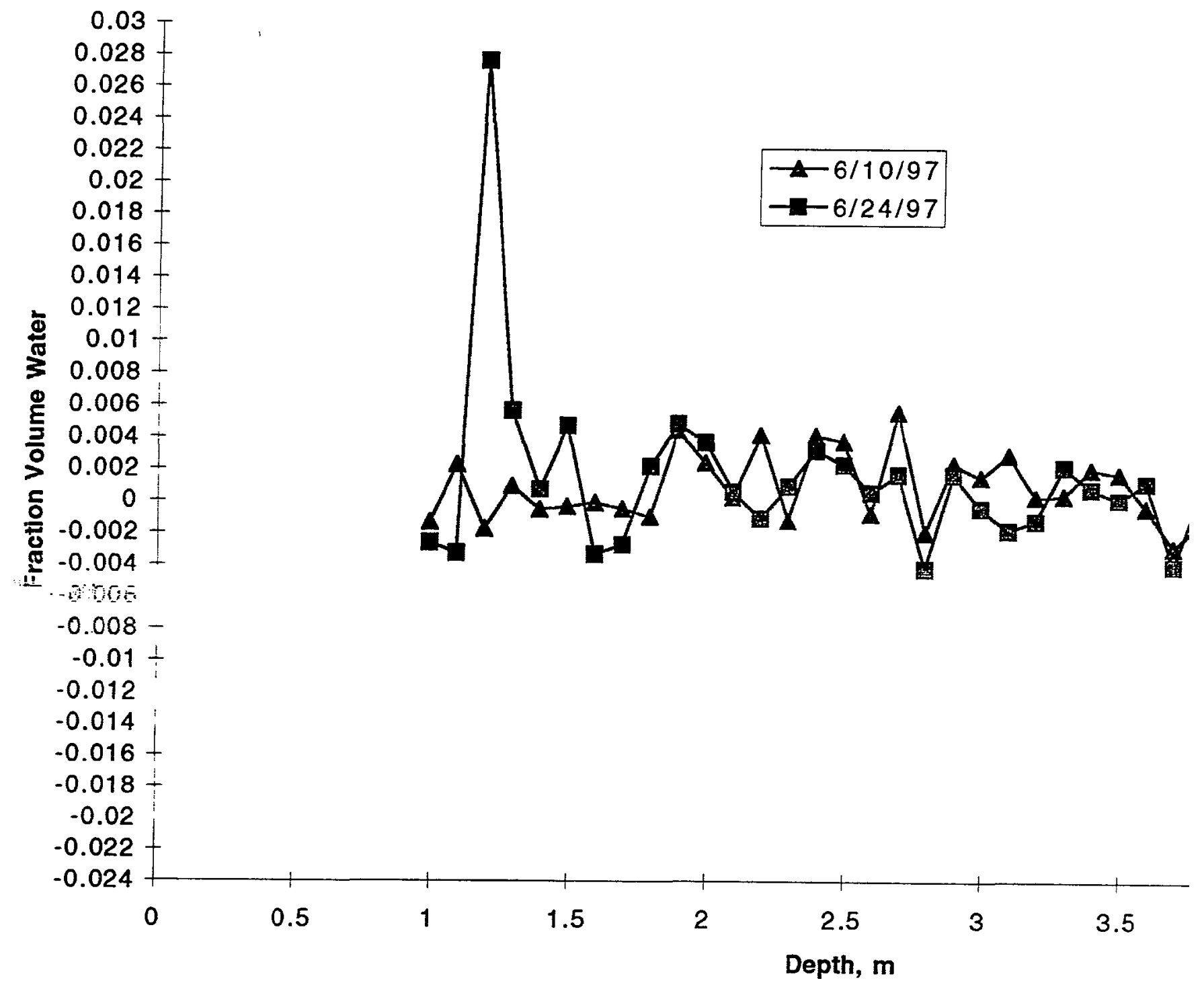

Figure 27. Difference fraction volume water content in Hole\#22 as a function of depth 6/24/97. 


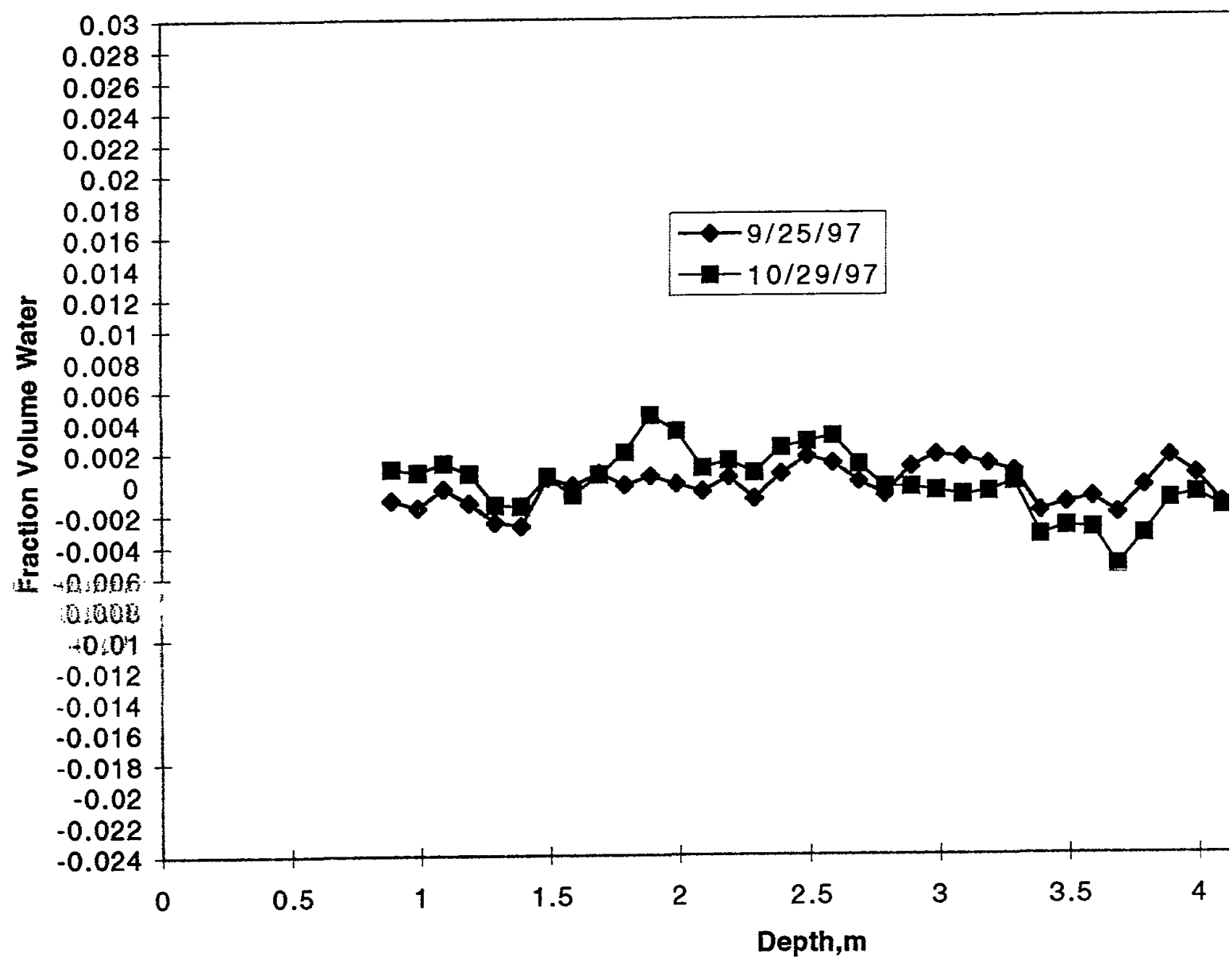

Figure 29. Smoothed difference fraction volume water content in Hole\#22 as a func collar on 9/25/97 and 10/29/97. 


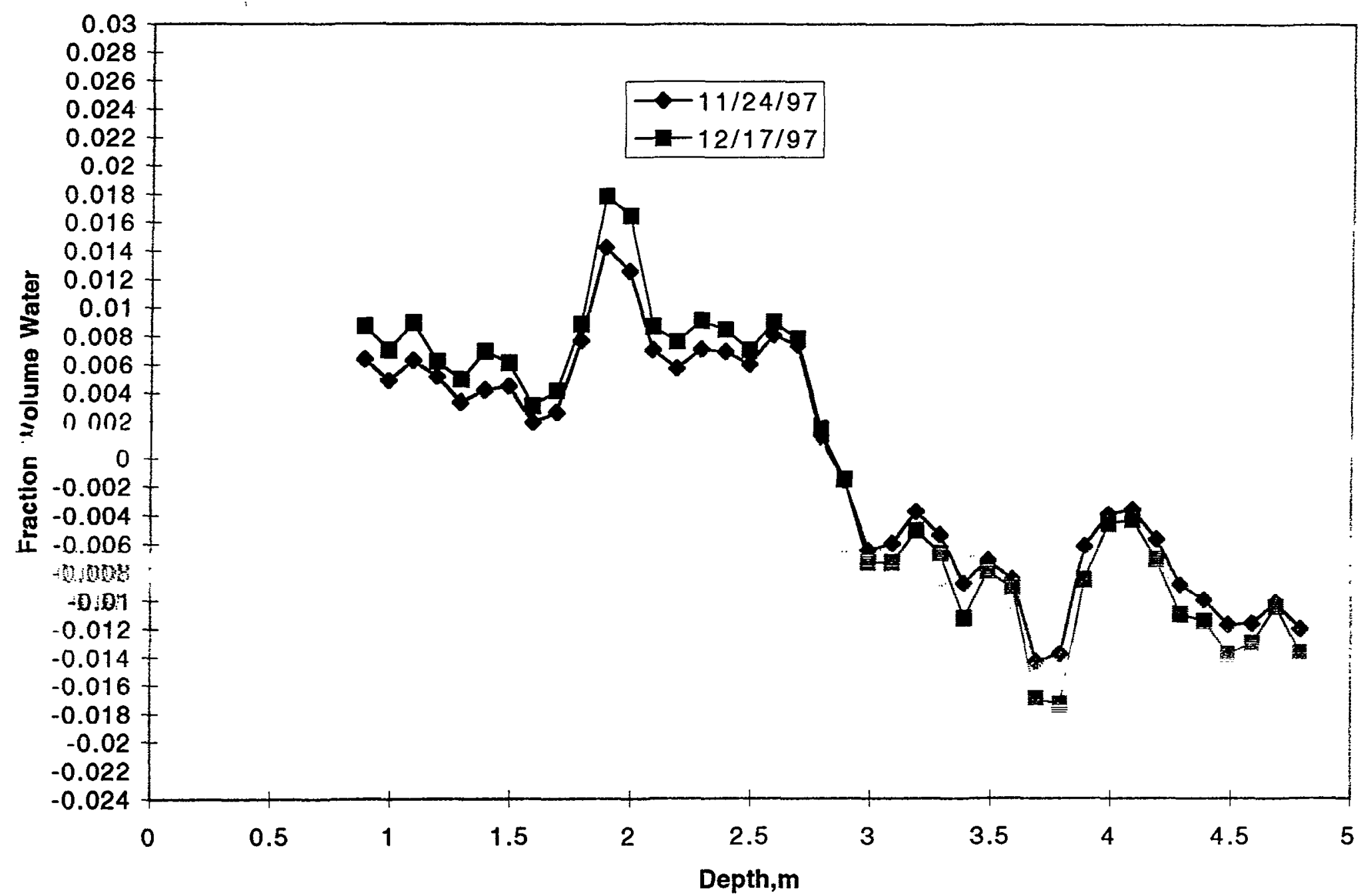

Figure 30. Smoothed difference fraction volume water content in Hole\#22 as a function of depth from collar on $11 / 24 / 97$ and $12 / 17 / 97$. 


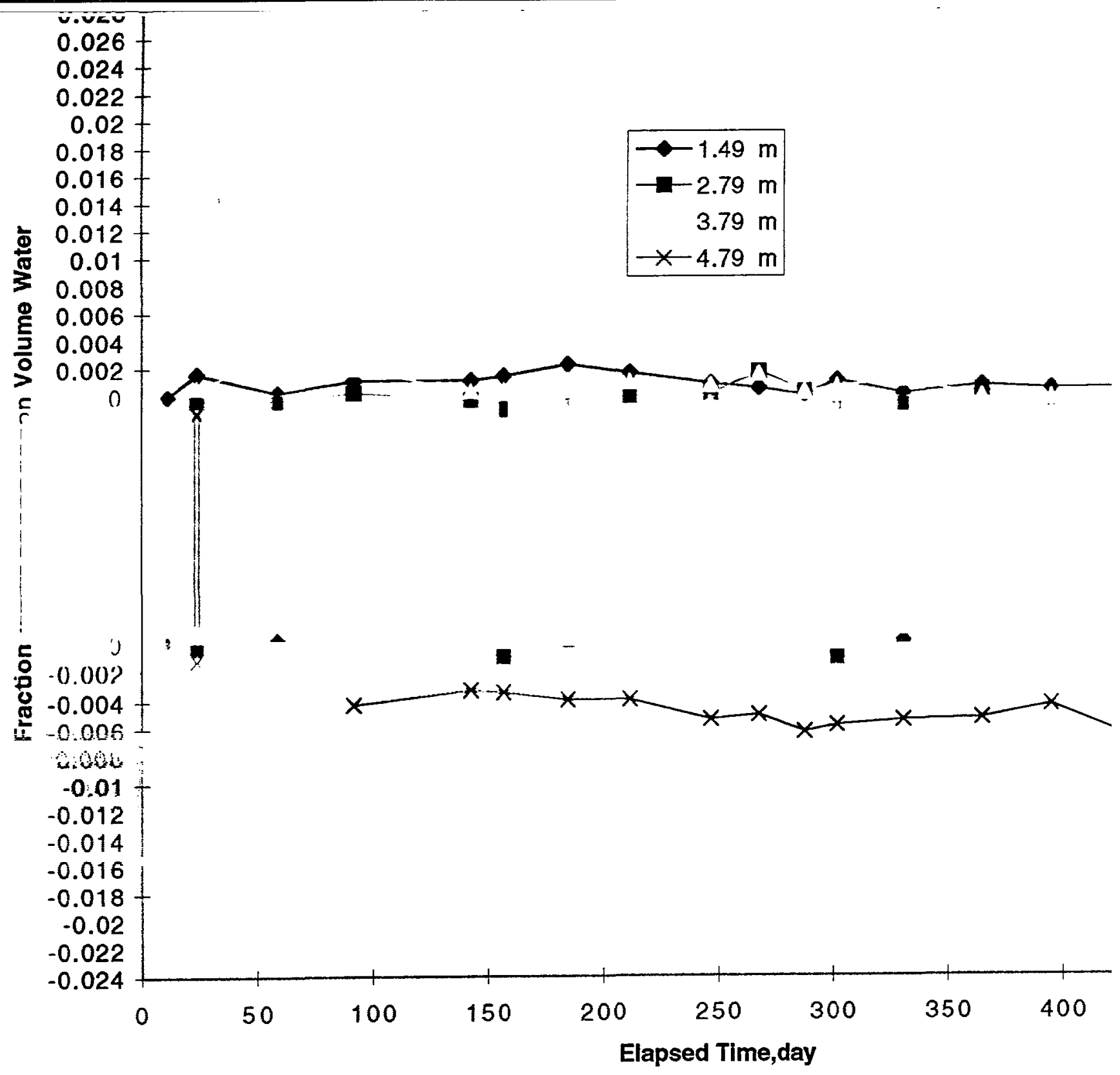

Figure 31. Smoothed difference fraction volume water content at various depths from as a function of time. 


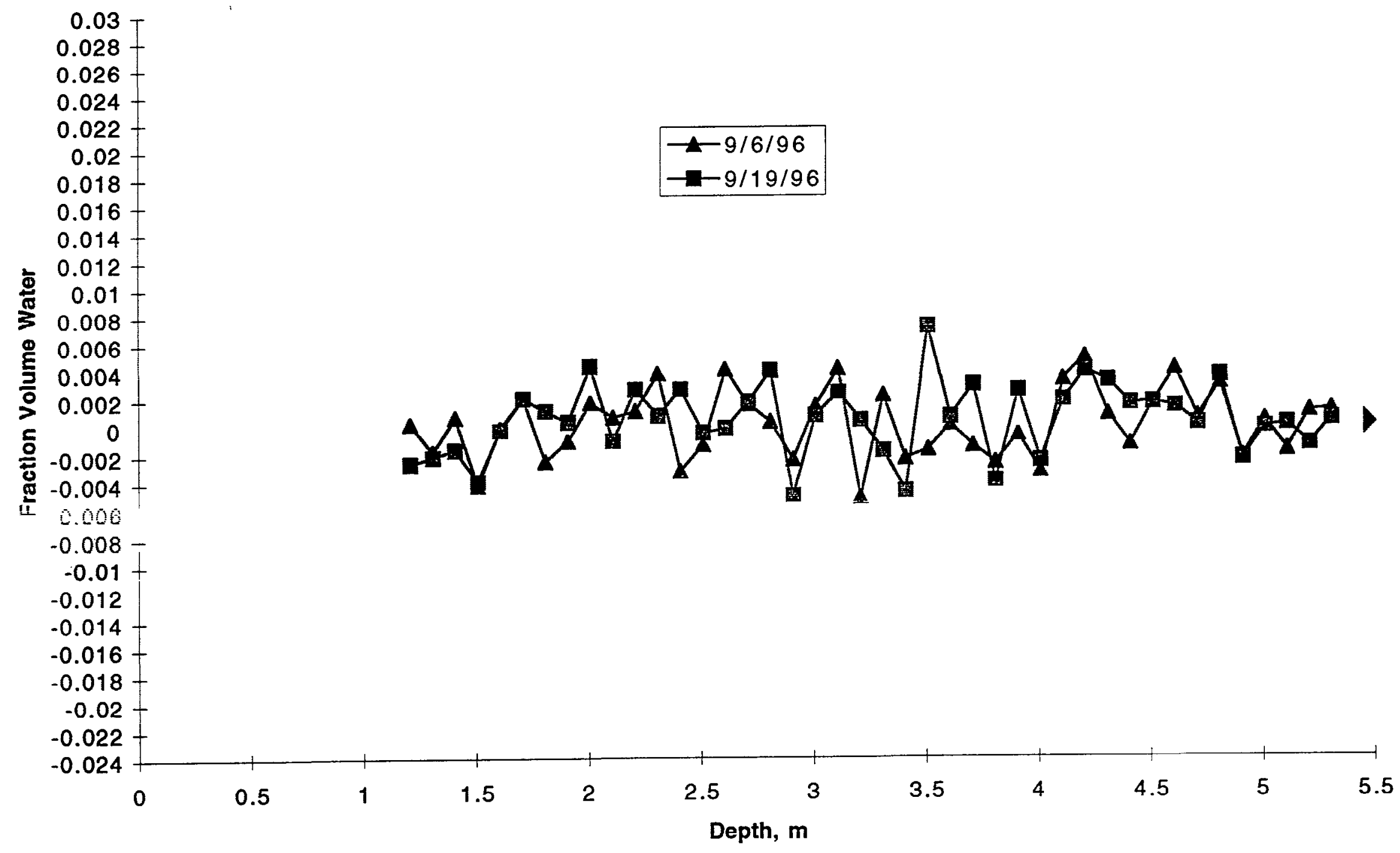

Figure 32. Difference fraction volume water content in Hole\#23 as a function of depth from collar on 9/6/96 and 9/19/96. 


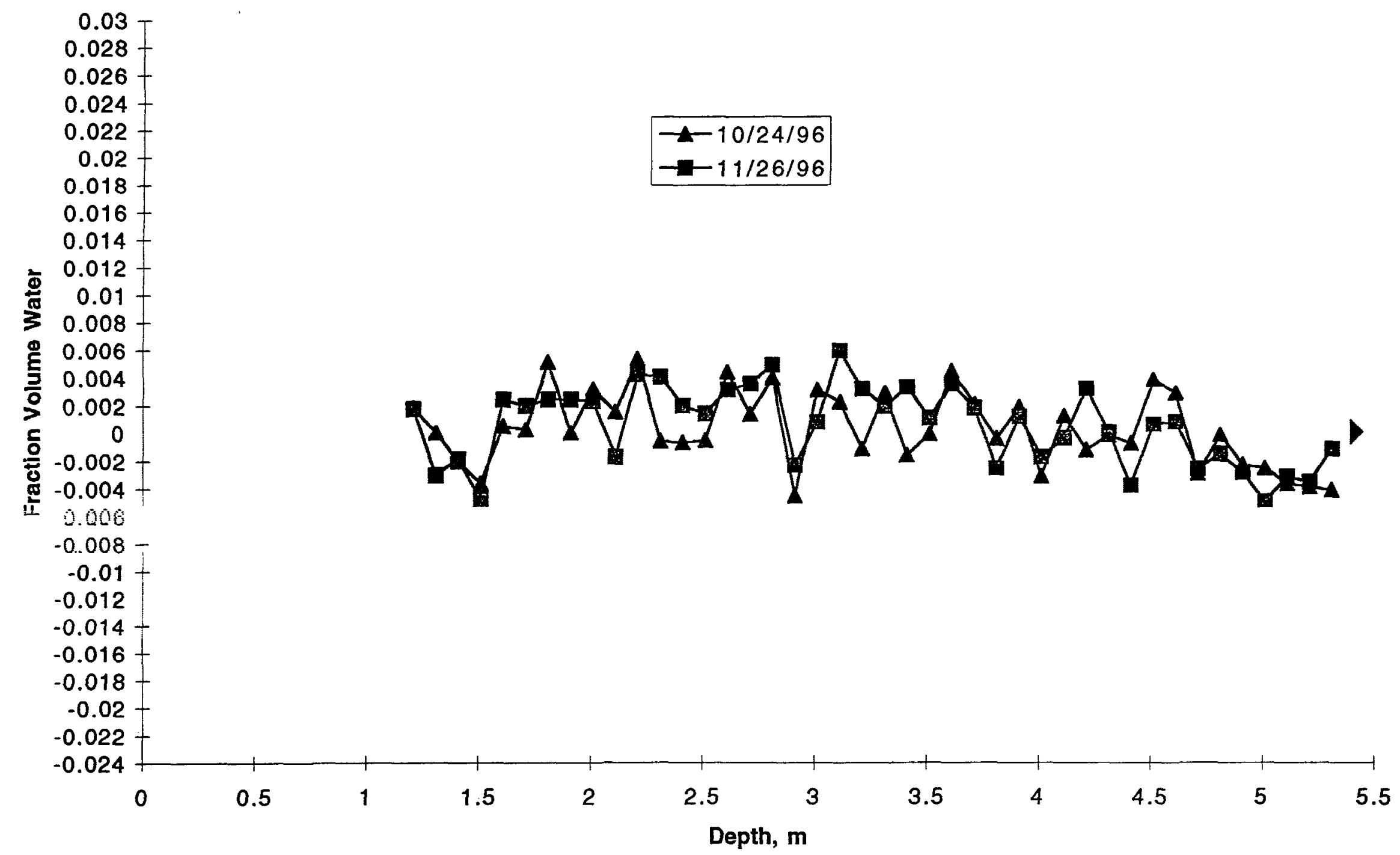

Figure 33. Difference fraction volume water content in Hole\#23 as a function of depth from collar on 10/24/96 and 11/26/96. 


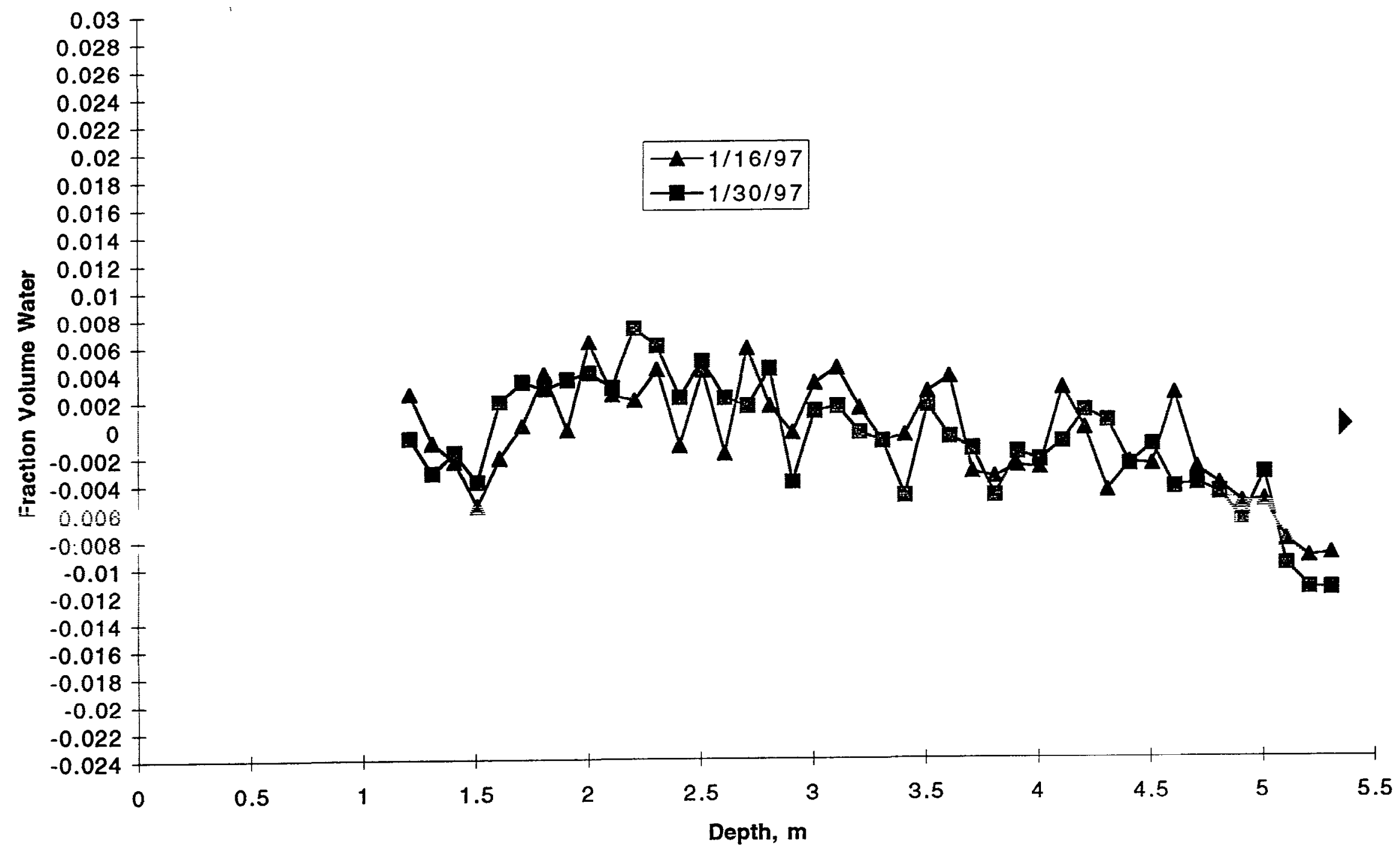

Figure 34. Difference fraction volume water content in Hole\#23 as a function of depth from collar on 1/16/97 and $1 / 30 / 97$. 


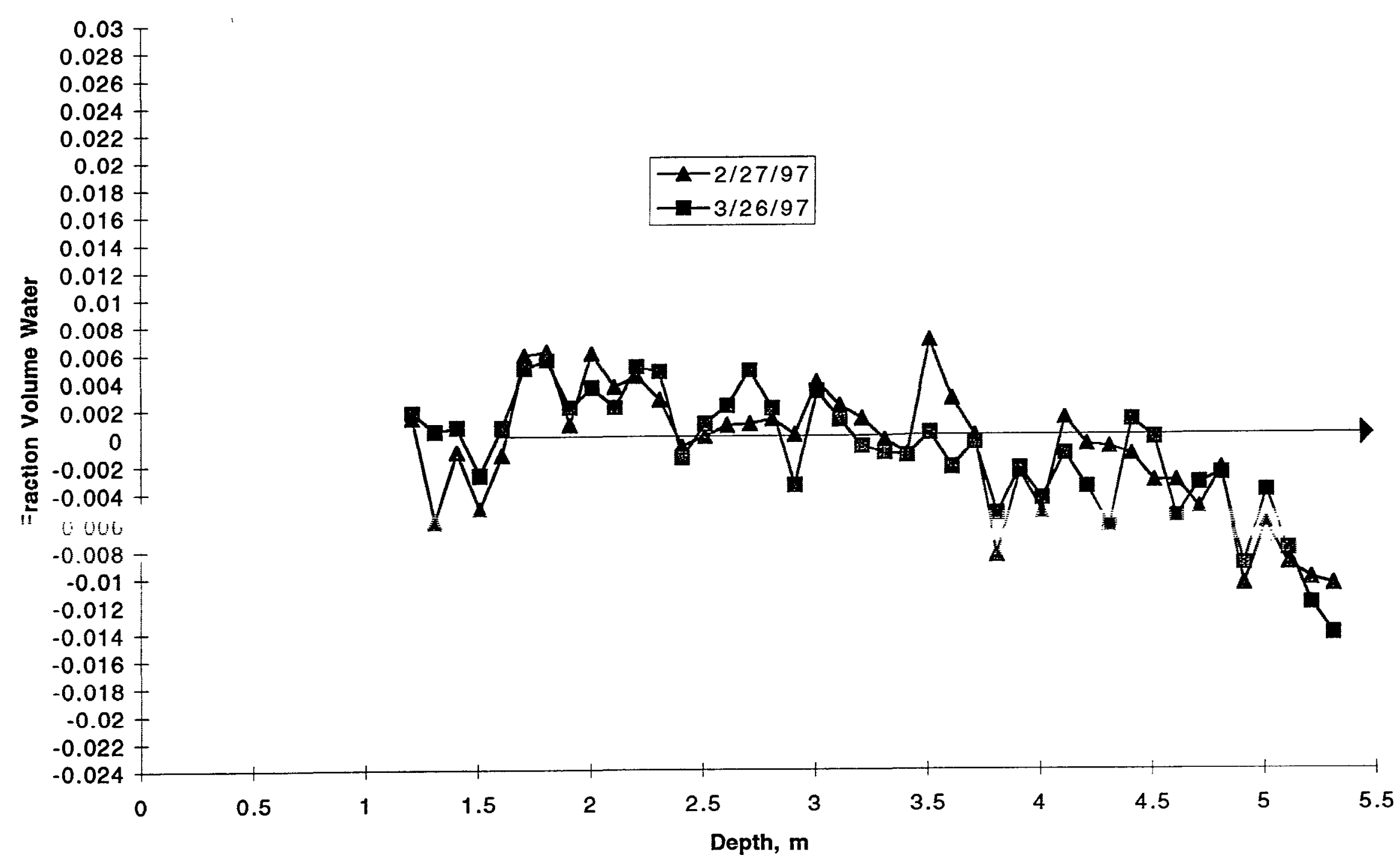

Figure 35. Difference fraction volume water content in Hole\#23 as a function of depth from collar on 2/27/97 and $3 / 26 / 97$. 


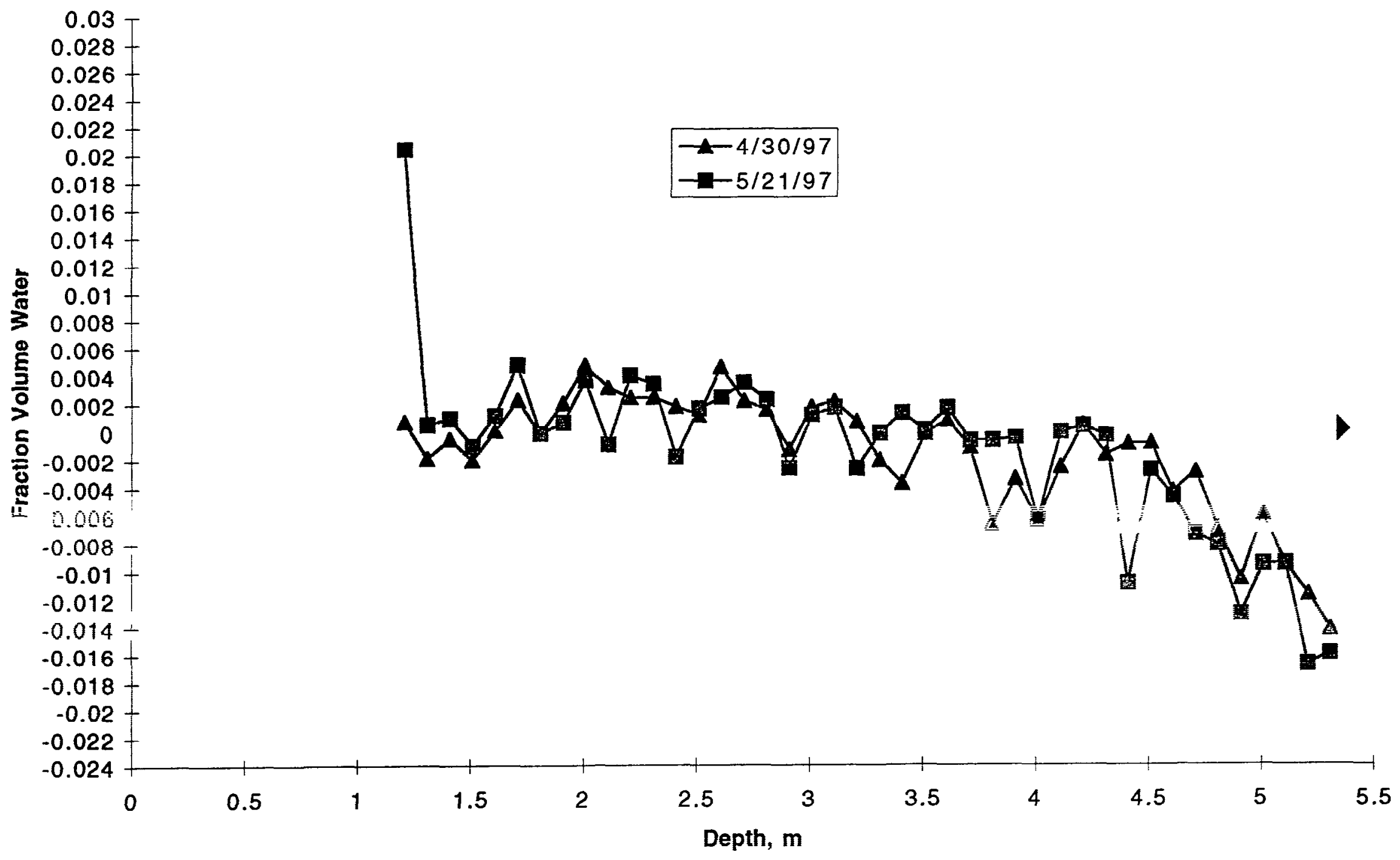

Figure 36. Difference fraction volume water content in Hole\#23 as a function of depth from collar on 4/30/97 and 5/21/97. 


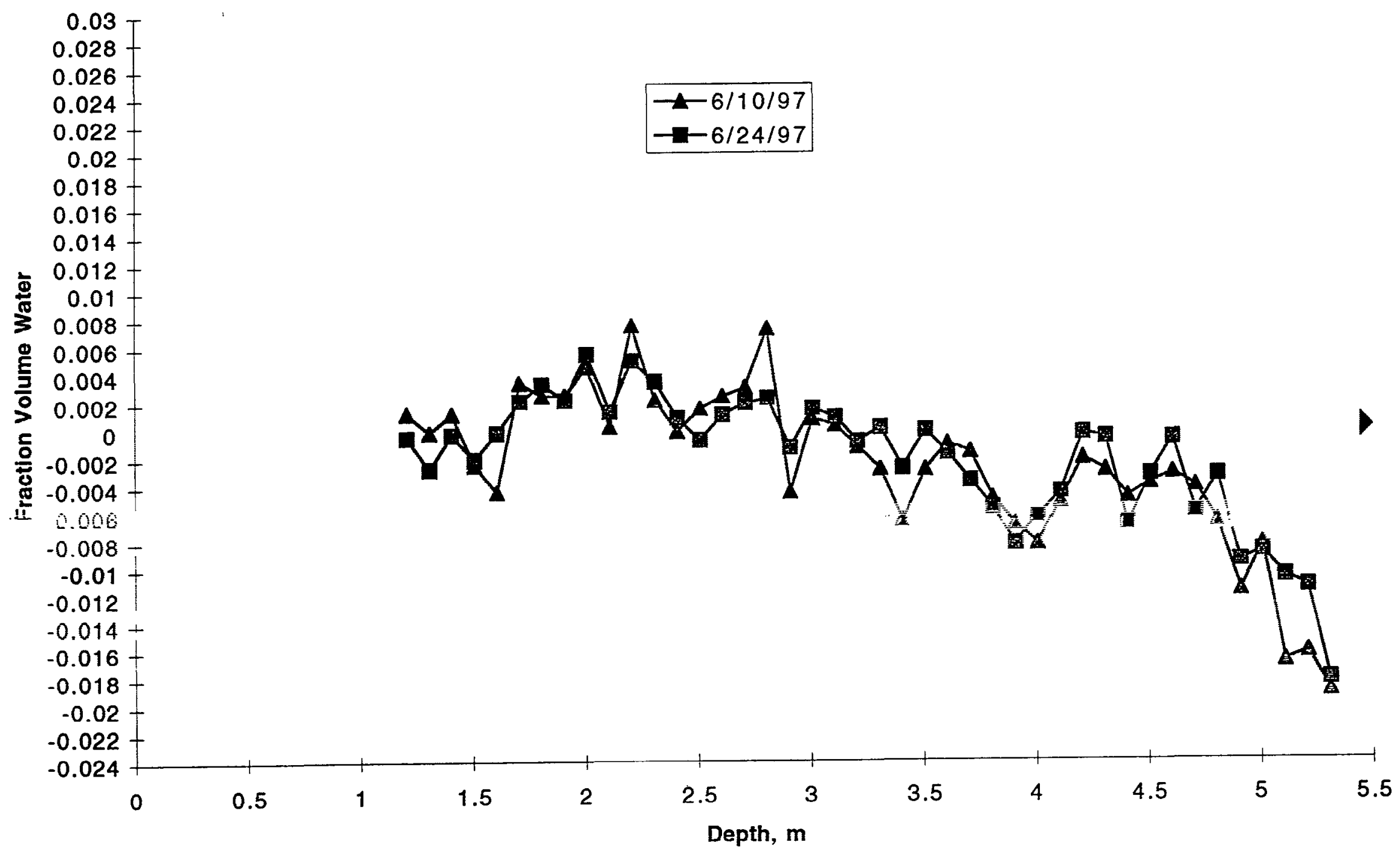

Figure 37. Difference fraction volume water content in Hole\#23 as a function of depth from collar on 6/10/97 and 6/24/97. 


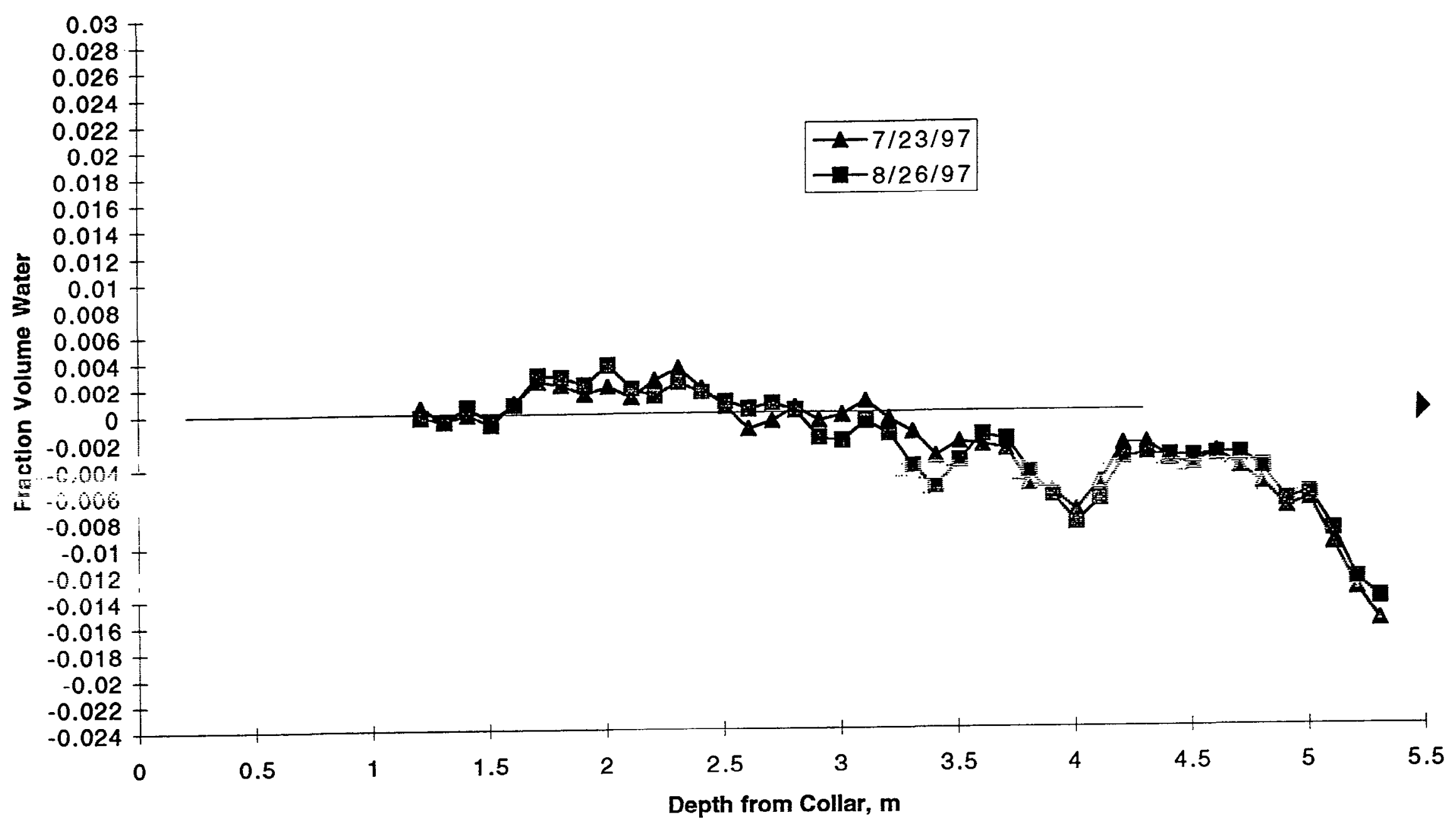

Figure 38. Smoothed difference fraction volume water content in Hole\#23 as a function of depth from collar on $7 / 23 / 97$ and $8 / 26 / 97$. 


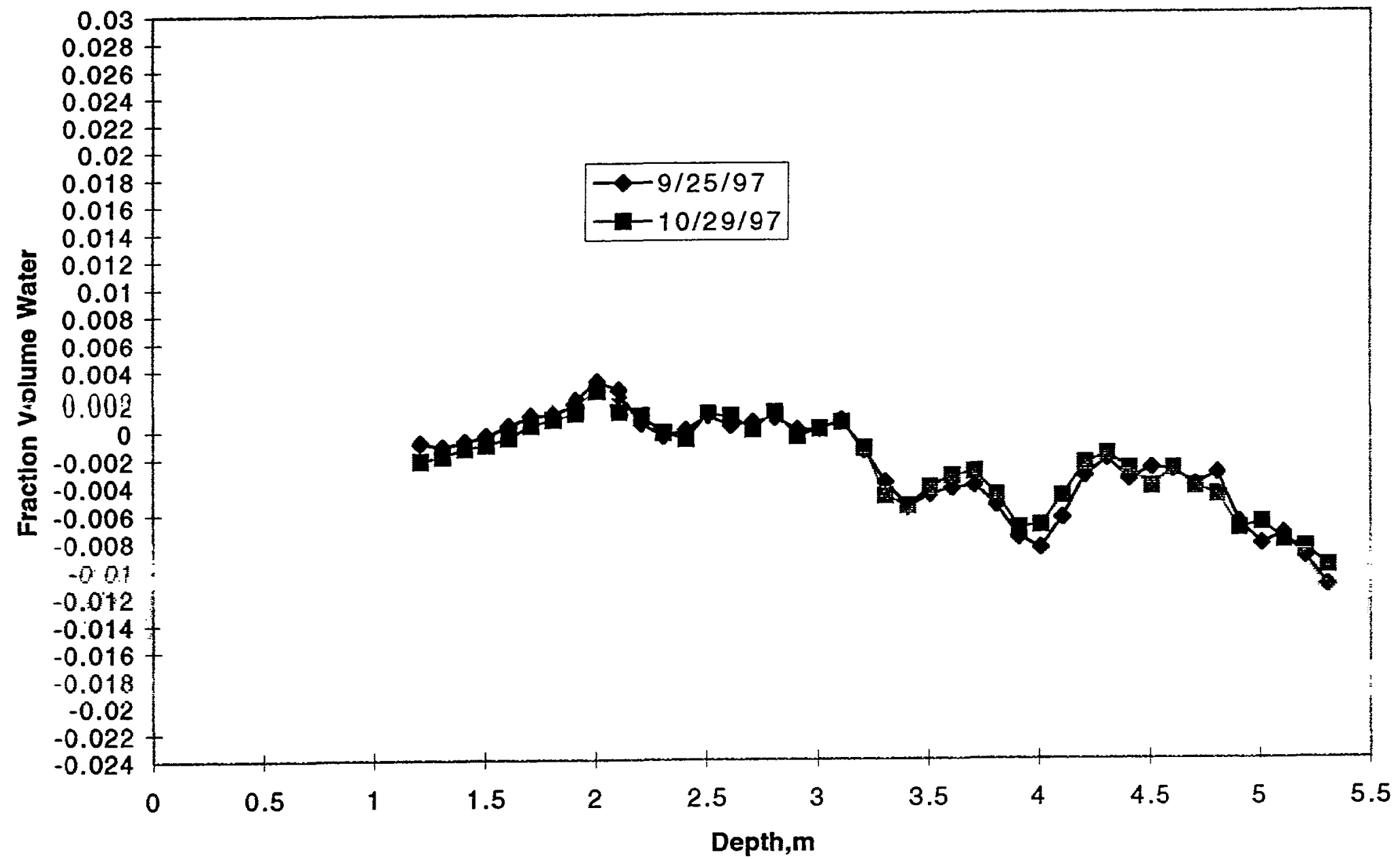

Figure 39. Smoothed difference fraction volume water content in Holeł23 as a function of depth from collar on $9 / 25 / 97$ and 10/29/97. 


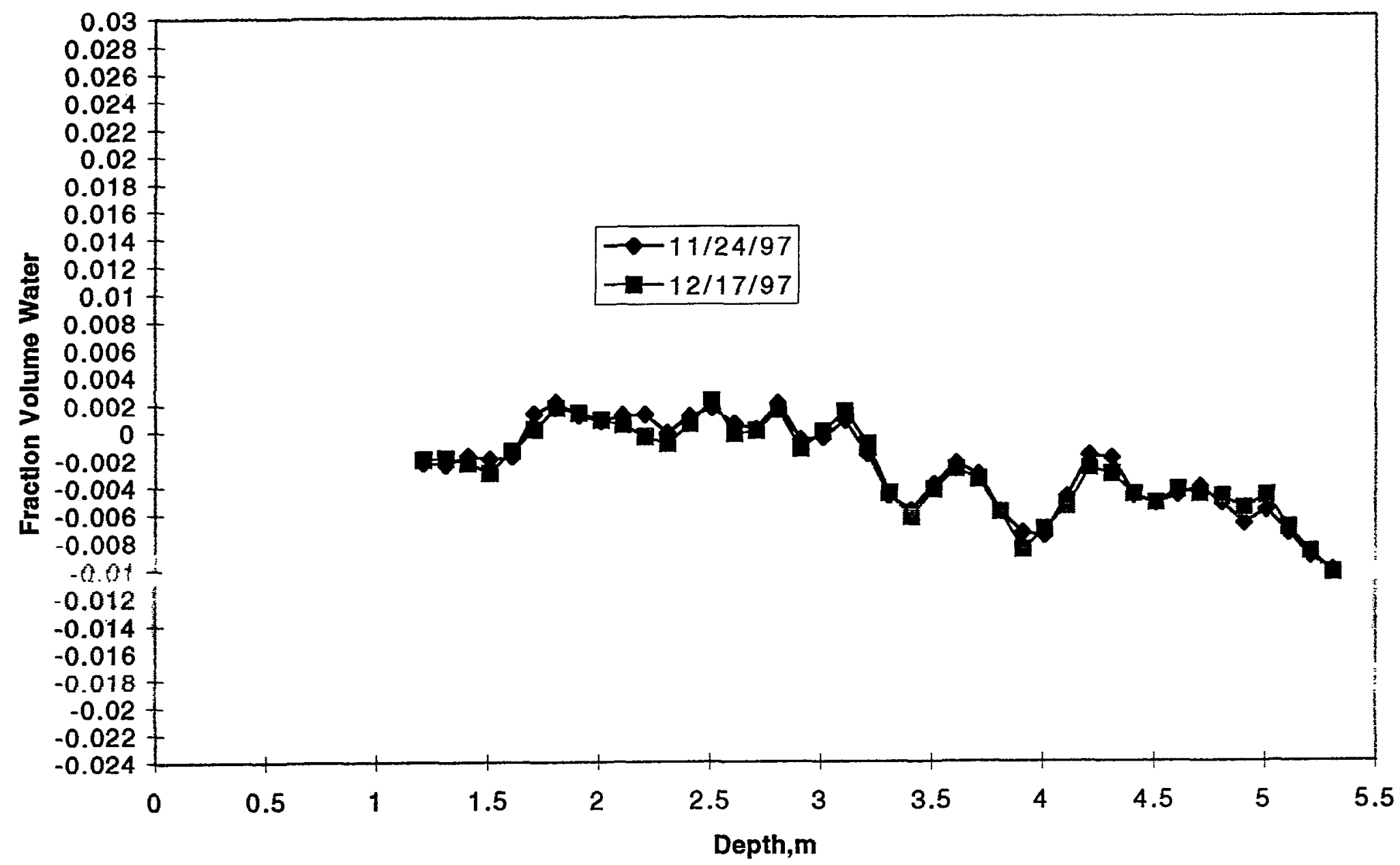

Figure 40. Smoothed difference fraction volume water content in Hole\#23 as a function of depth from collar on 11/24/97 and 12-17/97. 


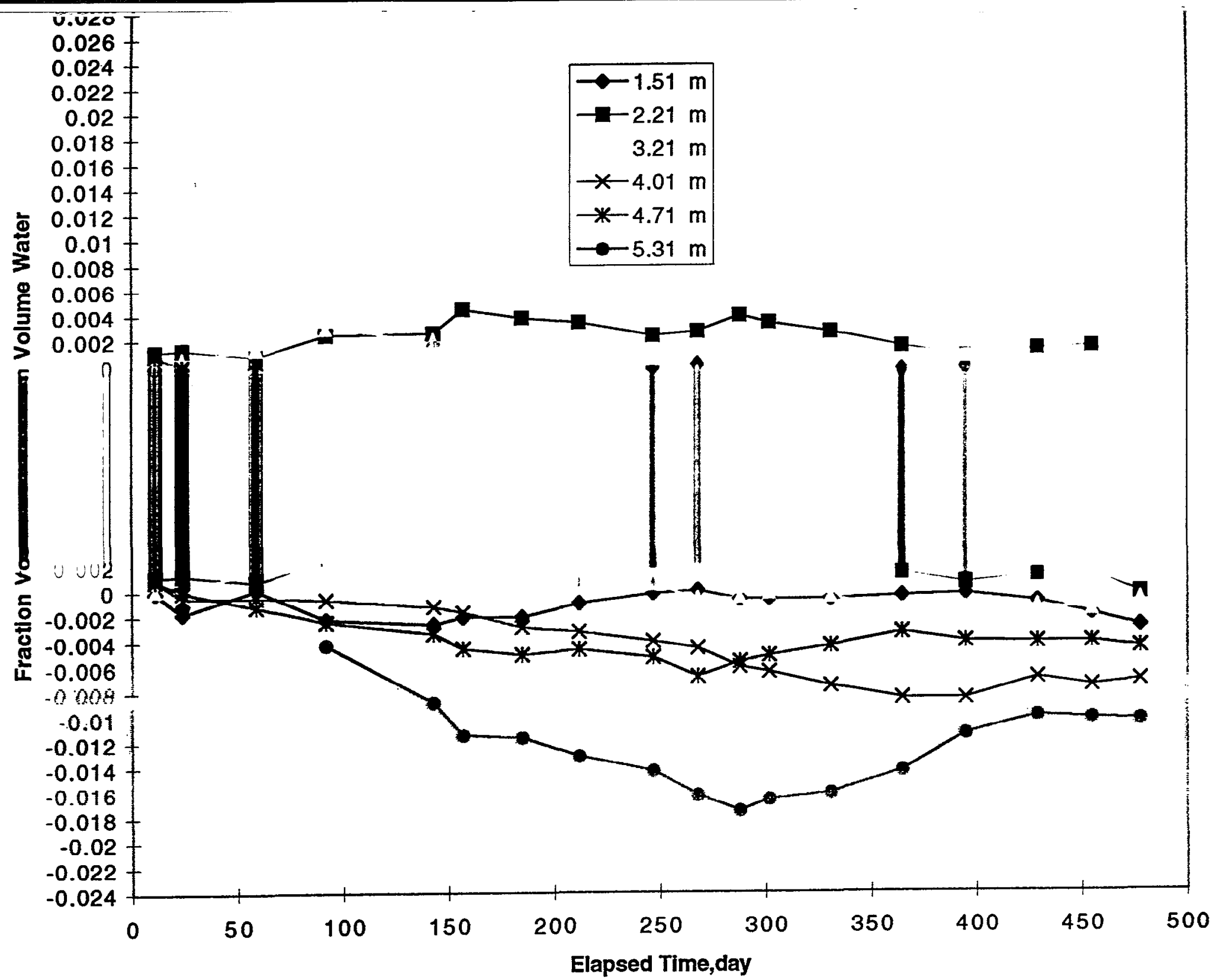

Figure 41. Smoothed difference fraction volume water content at various depths from collar in Hole\#23 as a function of time. 


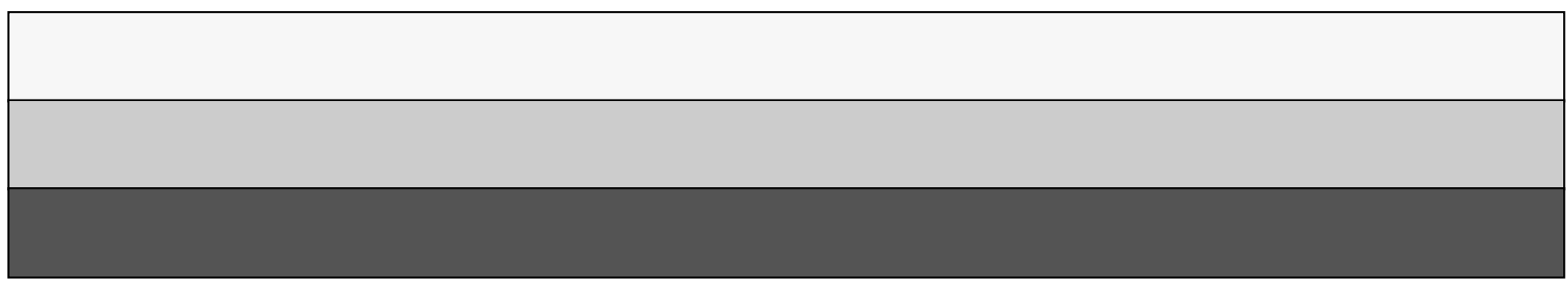

